\author{
DEVELOPMENT, TESTING AND EVALUATION OF \\ MHD-MATERIALS \\ Quarterly Report \\ for the period Jan. - March, 1976
}

H. P. R. Frederikse, T. Negas and S. J. Schneider

Inorganic Materials Division

Institute for Materials Research

National Bureau of Standards

Washington, D. C. 20234

Date Published: March 31, 1976

\author{
PREPARED FOR THE UNITED STATES \\ ENERGY RESEARCH AND DEVELOPMENT ADMINISTRATION \\ Under Contract No. E (49-18) -1230
}

\title{
IMFORTANT HONICE
}

MATIONAL BUREAU OF STANDARDS REPORTS are usualiy preliminary or progress accounling occuments intended be use within the Government. Eetare materisl in the reports is formally bublished it is subiecied io addilionat evaluation and review. For this reason. the publteation. reprinting. peproduction. or onen iterature listing of this Reoort, either in whole or ir fart, is no: autincriad uniess permission is ozianed in writing from the Olfice of ine Dieclor, National Bureas of Slar Jards. Washing:cn. O C. 20234 . Such cermission is not riceded, honever. Oy the Government agency for which the Report has deen specilically prepared if inat agency wishes to reproduce addilional copies for tts own use. 



\section{ABSTRACT}

During this quarter activities were focused on the characterization of the electrode materials tested in the U-02 MHD facility in september 1975 (Phase I). A Final Repcrt about all aspects of this test, including contributions from Westinghouse, Battelle Northwest, and from the Soviet team, is in an advanced stage of preparation.

Conclusions derived from the post-test evaluation are being used to plan Phase II of the U-02 Materials Testing Program. During a meeting of the US-USSR Working group - in which several NBS staff members participated it was decided that mid-August will be the target date for the next U-02 test.

In this quarter, collection of data on structural, chemical and electrical properties of spinels has been emphasized, because these substances show great promise as electrode materials; one or two of them probably will be tested in the U-02 facility this summer.

In February ERDA requested the Bureau to assist in the evaluation of channel wall materials after a 95 hour test of the AVCO MHD generator. A number of anode and cathode elements have been received and prepared for optical, X-ray and SEM experiments.

Other activities listed under Tasks $I, J$ and $L$ are being continued. 5 The work on viscosity of coal slags is concerned with the effect of various redox conditions. Vapor pressures of $\mathrm{K}_{2} \mathrm{O}$ over slags of different compositions have been measured and analyzed. 'SEM studies of K-diffusion into alumina are now beyond the "try-out" stage. The first phase of the assessment of downstream components, defining performance requirements, has been completed; efforts are now being concentrated on the problem of metal alloy corrosion by potassium vapor. 

The overall objective of this program is to obtain chemical and physical definition of high temperature materials which have shown promise for use in coal-fired open-cycle MHD power systems. Major problem areas in which investigations will be concentrated are:

1. Characteristics of coal slag and its effects on system components and performarce at prototype temperatures.

2. Development of electrode materials which provide adequate performance over extended periods of time.

3. Insulating materials which limit thermal losses and are resistant to prolonged thermal and erosion effects.

4. Preheater materials which can withstand the operating modes of separately and directly fired operation.

5. Seed recovery methods from slag which are technically and economically feasible.

6. Phase equilibria and diffusion rates of seed in slag and the corrosive action of combination on system components and materials.

7. Lurability of prototype MHD sub-systems.

The program is designed to contribute to the solution of these problems by providing much needed data on candidate materials and by evaluating test samples and structures that have been subjected to real or simulated MHD conditions. The activities are grouped under six tasks:

G. Program Management Coordination (Assisting ERDA in coordination, planning and review of the various MHD-Materials Development Programs).

H. U-02 Materials Testing and Characterization (Coordination of U-02 Test Activities, Phase I).

I. Operational Design Properties (viscosity, electrical conductivity, vaporization).

J. Corrosion by seed and Slag (phase equilibria, diffusion).

K. Materials Testing and Characterization 'test coordination, pre- and post-test analysis).

L. Assessment of Steam Plant Components (corrosion resistance of metals and alloys). 

Task G. Program Management Coordination

- Conducted a meeting of the U.S. members of the Working Group for MHD Materials in January 1976. Participated and chaired sessions of the US-USSR MHD-Materials Working Group in February 1976. At both meetings Phases I, II and III of the U-02 Materials Testing Program and the testing of Soviet MHD-materials in the U.S. were discussed.

Task H. U-02 Materials Testing and Characterization

- Finalized the post-test experiments conducted at NBS (Phase composition, electrical conductivity, radiography).

- Completed the draft of the U.S. parts of the Final Report describing the U-02 materials test (Phase I).

\section{Task I. Operational Design Properties}

\section{a. Viscosity of Coal slag}

- Iridium parts were received for adaptation of the viscometer to extend mea surement to $1800{ }^{\circ} \mathrm{C}$.

- Preliminary measurements revealed that a reducing atmosphere (by bubbling "forming gas" through the melt) had no visible effect on the viscosity of slag. Bubbling of oxygen, however, increased the viscosity at $1370{ }^{\circ} \mathrm{C}$ by about $7 \%$.

\section{b. Electrical Conductivity}

- Conductivity measurements on more than a dozen Fe-doped spinels indicated that some of these substances may be good MHD electrode materials.

\section{c. Vaporization}

- Potassium pressures measured over two synthetic six-component slags were found to be significantly higher than the $\mathrm{K}$-pressures over $\mathrm{K}_{2} \mathrm{O}-\mathrm{SiO} 2$ solutions (with the same $\mathrm{K}_{2} \mathrm{O}$ concentration at the same temperature).

Task J. Corrosion Processes, Seed-Slag Interaction, Diffusion

- Exposure of $\mathrm{Mg}-\mathrm{Al}$ and $\mathrm{Mg}-\mathrm{Cr}$ spinels to seed $\left(\mathrm{K}_{2} \mathrm{CO}_{3}\right)$ indicated that the former shows good corrusion resistance, while the latter reacts readily with potassium forming $\mathrm{K}_{2} \mathrm{CrO}_{4}$. However, the chromite spinel appears to withstand attack by slag rather well; in this situation (when the spinel is covered with slag) the $\mathrm{K}$ corrosion will be diminished considerably.

- A refractory ceramic (spinel + MgO) tested by Fluidyne Engineering Corp. for slag corrosion is being characterized using SEM and EDX techniques. - Studies of potassium diffusion from (K) $\mathrm{B}$-alumina into pure $\mathrm{Al}_{2} \mathrm{O}_{3}$ are
being continued. 

Task K. Materials Testing and Coordination

- Electrical measurements and X-ray diffraction studies are being conducted on samples of materials that will be tested in the Phase II-U-02 experiment planned for August 1976. These samples include specimens fabricated at Westinghouse, Battelle and NBS.

- Electrode sections from the AVCO MHD channel wall that has been tested in a 95 hour run made in February at the AVCO Everett Laboratcries, are being analyzed and characterized at NBS (X-ray diffraction, SEM, etc).

'Cask L. Assessment of Steam Plant Components

- Environmental conditions (temperatures, pressures, etc.) are being collected from experimental data and model calculations performed by other organizations. These conditions (and hence performance requirements) for components "below" the preheater (or seed condenser) are constantly updated and modified.

- Reports are being analyzed dealing with the potassium corrosion resistance of various alloys (stainless steel, Inconel, Hastelloys, etc.) in the range $870-1000{ }^{\circ} \mathrm{C}$. 



\section{Accomplishments}

Most of the NBS work on MHD-Materials performed under this contract is closely interwoven wita the overall ERDA Program plans for MHD-development and hence, has to be aligned, nearly daily, with the direction in which these plans proceed. For that reason NBS keeps close contact with the ERDA-MHD Division and with the various contractors involved in generator testing, preheater evaluation, MHD system modeling, etc. Often NBS has to change its plans, put more emphasis on a particular aspect of the program, shift personnel for a certain period to the particular task that has highest priority, and consequently decrease the effort temporarily in other areas. Hence, the design of program plans has to be flexible, projected goals reconsidered and targets or target dates readjusted.

During the past $S$ months, Task $K$, Materials Testing and Coordination, has received by far the most attention. Most of the work has been connected, in one way or another, with the U-02 (Phase I) test conducted during last September in Moscow. Activities during July, August and September included the drafting and finalizing of detailed work plans for the Battelle Proof Test and the U-02 test, determination of physical or chemical properties of selected test electrodes and insulators, preparation and formulation of Phase I post-test activities as well as Phase II test plans, and finally participation in the U-02 test. Immediately after the experiment, efforts have been concentrated on the post-test characterization of materials. This included disassembly of the modules, recording and photographing of the various components, slicing of the cathode and anode sub-modules, preparation of these s.lices for X-ray diffraction, SEM, electroprobe, radiographic, thermophysical, etc. measurements. Around February 1, 1976 a first draft of the results of these measurements, including conclusions, was compiled.

Summing up the achievements of the NBS effort during the first 8 months of the contract in terms of the projected targets (milestones) as formulated in the original work statement the following completed goals can be listed:

(4a). Completed the first phase of the study concerned with the effect of alkali additions on the viscosity of coal slags.

(7). Determined the vapor pressure of $\mathrm{K}_{2} \mathrm{O}$ in the system $\mathrm{K}_{2} \mathrm{O}-\mathrm{K}_{2} \mathrm{SO}_{4}-\mathrm{SiO}_{2}$.

(16a). Determined the electrical conductivity of various coal slags as a function cf temperature and oxygen partial pressure. (The investigation of the dependence on electric field strength is continuing).

(19). Measured the eleztrical conductivity of promising electrode materials (in particular: $\mathrm{ZrO}_{2}: \mathrm{Y}_{2} \mathrm{O}_{3}, \mathrm{ZrO}_{2}: \mathrm{CeO}_{2}, \mathrm{Mg}-\mathrm{Cr}-\mathrm{Fe}$ spinels and $\mathrm{Mg}-\mathrm{Al}-\mathrm{Fe}-$ spinels).

(20). Designed, fabricated and installed equiprent for measuring electrical, mass-, etc. transport through a composite test electrode in a large temperature gradient.

(24). Determined the phase diagram for the systems $\mathrm{K}_{2} \mathrm{O}-\mathrm{ZrO}_{2}$. 

(27). Studied the phases and eutectics in the system $\left(\mathrm{K}_{2} \mathrm{CO}_{3}\right)-\mathrm{CeO}_{2}-\mathrm{ZrO}_{2}$. (28). Assessed the resistance of $\mathrm{CeO}_{2}$-based materials to seed corrosion.

(30a). Evaluated, selected and procured equipment (an AMR Scanning Electron Microscope and Energy Dispersive X-ray analyzer) for the measurement of diffusion of seed (and other elements and compourds) into MHD materials.

(3la). Completed preliminary test experiments aimed at the determination of the rate of diffusion of certain species (potassium) into alumina, magnesia, etc. ceramic bodies.

(39). Coordinated testing and pre- and post-test analysis of specimens exposed to (simulated or) real MHD conditions in (a variety of test rigs, arc heaters, small-and) large-scale MHD generators. [U-O2 (Phase II) AVCO, Westinghouse, etc.].

(40). Used a variety of chemical and physical techniques to assess the degradation of certain chromites and aluminates tested for specific time periods in a stinulated MHD preheater test facility (at Fluidyne Engineering Corp) .

(41a). Analyzed and compiled (from data and experiences of MHD facility operators) the range of environmental conditions, under which steam plant components must function. 

U.S.-U.S.S.R. Materials Program Activities

During this reporting period two meetings of the Materials Working Group took place. Four NBS staff members participated: S. J. Schneider (chairman), H. P. R. Frederikse, w. R. Hosler and T. Negas. On January 15 (at NBS) and on January 16 (at ERDA Headquarters) the U.S. Group met for the purpose of briefing ERDA staff on the results and conclusions of the U-02 test-Phase I, and furthermore to plan and establish strategy for the forthcoming meetings (February 1976) with the USSR Materials Group.

The status of the Phase I results and conclusions is described in another section (Task $\mathrm{H}$ ) of this report. It was the consensus that plans for the Phase II, U-02 test (scheduled for June 76) should proceed as originally communicated to the Soviets during the October 1975 meeting (100-200 hour test, relevant to U-25 channel development, $\mathrm{K}_{2} \mathrm{SO}_{4}$ seed if agreeable to Soviets). The main inhibiting factor in meeting the June test was the lack of time necessary to test, select and prepare candidate test materials. The primary materials however would be improved (microstructure) Phase I. electrodes. Plans for Phase III were also formulated. This test would be based on replenishment (Fe-Al-Silicate) and would be conducted through a joint effort with each side having responsibility for design, construction and testing.

During the February 1976 meeting with the Soviets the above positions were negotiated. The U.S.S.R. side agreed to proceed with Phase II plans as presented by the U.S. side; however, the target date for the test was shifted to mid-August 1976. Phase III plans were not agreed to entoto but major points were acceptable. The Steering Committee at its June meeting will hear detailed plans from both sides. The Soviets did not transmi.t all the documents they originally agreed to (Chapters for the Phase I report and for the Joint Status Report). These will be furnished by Māy 1976 . The testing of U.S.S.R. materials at Westinghouse and UTSI will begin in the Fall of 1976, as scheduled. A. J. Armstrong of NBS attended meetings with the Soviet Materials Group at Westinghouse (Feb. 23) and at UTSI (Feb. 24) at which the work plansfor these tests were discussed.

MHD Workshop on Replenishment

As indicated abore plans for Phase III of the US-USSR Materials Testing Program include the use of a replenishment material. To provide background and clocumented information about this aspect of MHD generators an ERIA sponsored workshop was held at NBS on December 17, 1975. Thirty-five persons representing the major institutions and companies involved in MHD attended this one-day meeting. Ten papers were presented discussing various replenishment (maintenance) materials and procedures, including zirconia and fly ash injection. A report covering these presentations and the subsequent discussions will be published shortly. 

Task H. U-02 Materials Testing and Characterization (Phase I)

a. Post Test Characterization (W. R. Hosler)

The U.S. portio is of the "Final Report on the U-02 Materials Test (Phase I)" has been completed. A version of Chapter I vritten by the Soviet participants, was presented in February to the Editor of the Final Report ( $W$. R. Hosler) and has been incorporated into the draft report. Soviet contributions to Chapters IID, III and IV have not yet been received. The Final Report is divided into four Chapters:

Chap. I. Description of the Test Facility and Operating Conditions During the Test (USSR)

Chap. II. Module Description, Analytical Procedures and Results of Analysis (US and USSR)

A. Module Design and Materials Preparation (Westinghouse)

B. Pre-test Characterization

a. Thermal diffusivity, thermal expansion, chemical composition, microstructure (Battelle)

b. Electrical conductivity, phase composition (NBS)

c. Porosity and pore size distribution (Westinghouse)

c. Post-Test Characterization

a. Module disassembly, phase composition, electrical conductivity, radiography (NBS)

b. Metallography and electron microprobe analysis (Battelle)

D. Soviet Results on Pre- and Post-test Characterization (USSR)

Chap. III. Comparative Analysis (with previous Soviet tests and test results) (USSR)

Chap. IV. Conclusions (US and USSR)

The Final Report will contain an extensive description of all stages of the test; the preparation and checks made before the test, the procedures followed and measurements performed during the test, and the analysis of the: materials after the test. For detailed information concerning any aspect of the test we refer the reader to the Final Report, which will be available later this year. A paper giving a condensed account of the entire U-02 test (Phase I) and materials characterization will be presented by S. J. Schneider at the 15th Symposium on the Engineering Aspects of MHD (May 24-26, 1976, Philadelphia, PA).

For purposes of this Quarterly Report we will present a few details involving the items mertioned in Section C.a. of Chapter II.

1. Module Disassembly (W. R. Hosler, A. J. Armstrong)

As discussed in the previous Quarterly Report (December 31, 1975) several slices of each of the 5 sub-modules were obtained by sawing lengthwise through the electrode assembly. Figures $l a$ and $l b$ show a photograph of cathode and anode cross sections of each of the 5 sub-modules. The numbers correspond to the last or last two digits of the 4-digit identification used for. labeling the electrodes (See Fig. 2). 



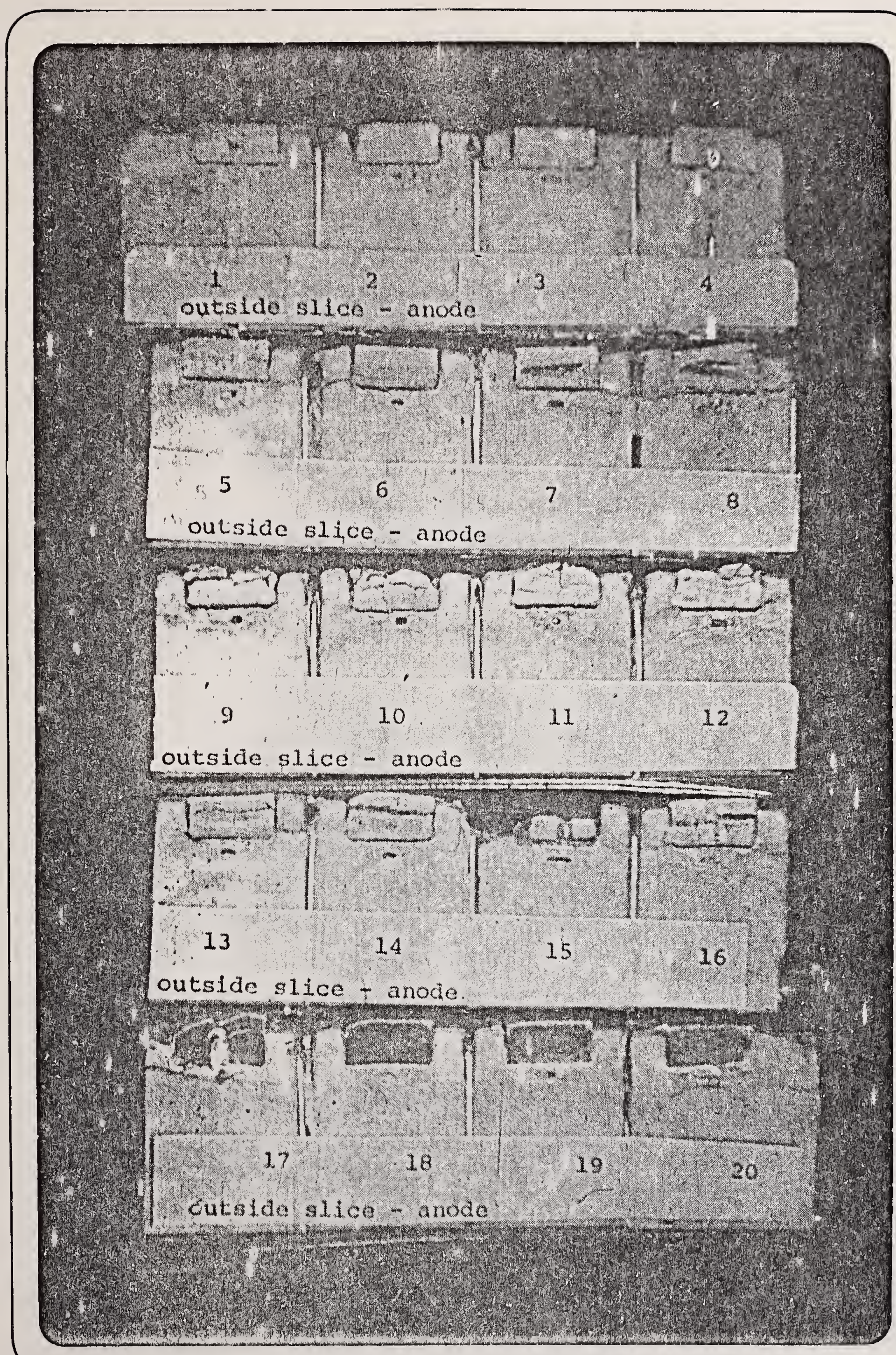





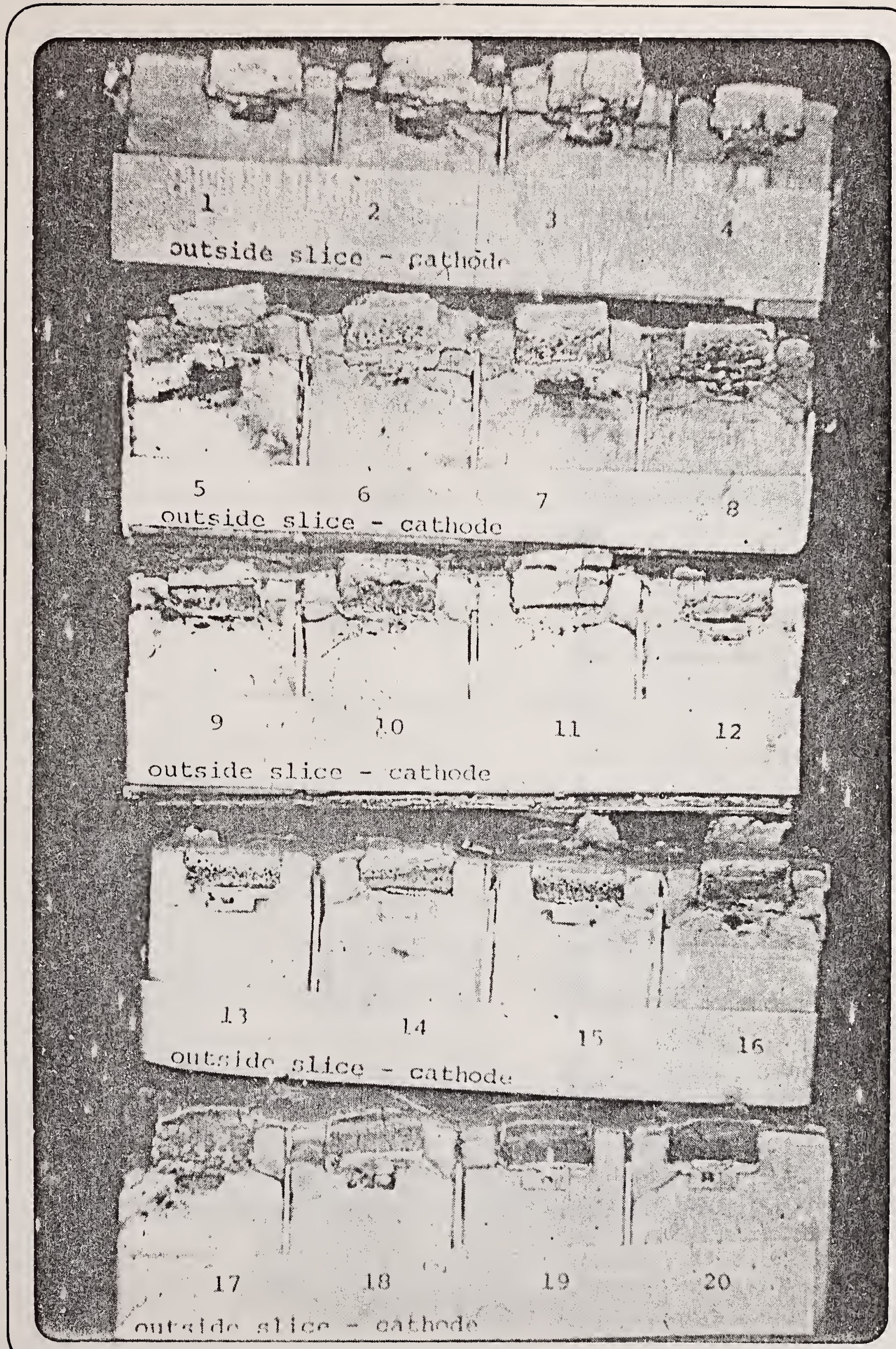





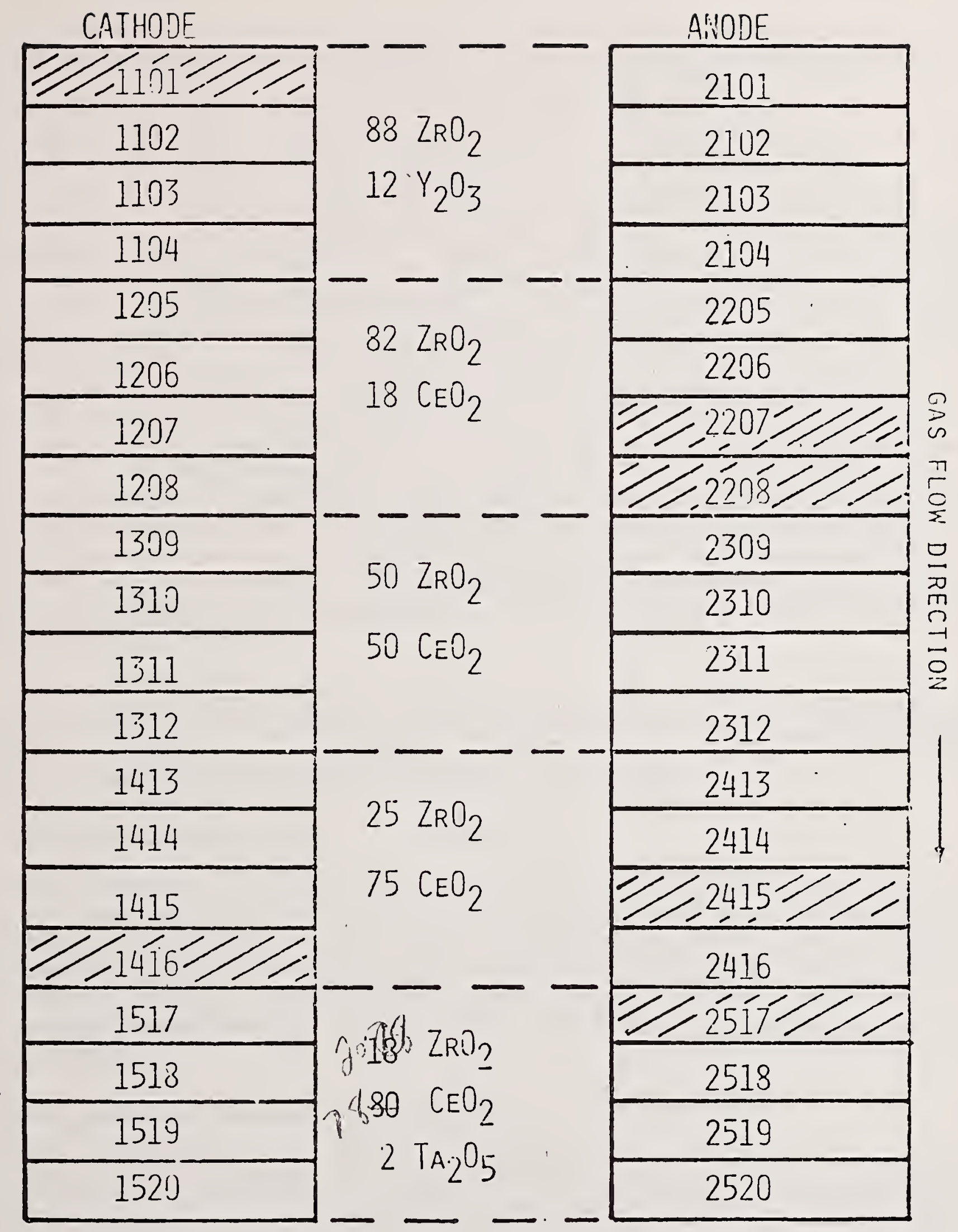

FIG. 2 .

SCHEMATIC OF CATHODE AND ANODE SHOWING MATERIALS, IDENTIFICATION DIGITS AND ELECTRDDE LEAD-OUT FAILURE. SHADED AREAS INDICATE WHICH LEAD FAILED (ANODE OR CATHODE). 

2. Phase Analysis of Materials (T. Negas, C. McDaniel, A. Perloff)

The results of $x$-ray phase analysis of electrodes utilized in the U-02, Phase I test, are summarized in Tables I and II. Several conclusions are reached based on these data together with a working knowledge of how $\mathrm{ZrO}_{2} /$ cerium oxide materials behave as a function of temperature and $\mathrm{P}_{\mathrm{O}_{2}}$ (see for example, Quarterly Report, March 31, 1975). Cathode materials containing $\mathrm{CeO}_{2}$ were subjected to reduction caused by low (partial) oxygen pressure or by electric field controlled mass transport. It is difficult to separate these two factors based on this test. Additionally, potassium seed penetrated the cathode ceramics, probably via cracks, pores and through the surrounding porous cement. Identification of $\mathrm{Ce}_{2} \mathrm{Zr}_{2} \mathrm{O}_{7}$, pyrochlore (actually reoxidized during cool-down) plus monoclinic $\mathrm{ZrO}_{2}$ in the materials is a strong indicator of reducing conditions, while the compound having the approximate composition $\mathrm{KCe}_{2} \mathrm{O}_{6}$ (a perovskite) obviously is a "marker" for reaction with $\mathrm{K}_{2} \mathrm{O}$. Reduction processes which may compromise the mechanical properties of pre-test, oxidized, $\mathrm{ZrO}_{2} / \mathrm{CeO}_{2}$ electrodes cannot be avoided at the cathode, unless electrodes are fashioned from pre-reduced materials. However, during the start-up and cool-down intervals of an MHD system, pre-reduced materials would be subjected to oxidation unless rapid start and stop procedures are utilized. Reactions with $\mathrm{K}_{2} \mathrm{O}$ may be minimized by reducing the porosity, controlling the cracking (if possible) and, perhaps, by ircreasing the backface-leadout temperature. What this optimum temperature should be is ill-defined although the condensation temperature range $\left(<1400^{\circ} \mathrm{C}\right)$ of seed provides a rough guide.

Supporting laboratory work together with a more detailed discussion of
: $\mathrm{ZrO}_{2} / \mathrm{CeO}_{2}$ materials is outlined in the manuscript of a paper (Chemical Aspects of Materials Containing Cerium oxide) to be presented at a meeting on ThermoPhysical properties to be held in Moscow in May 1976.

\section{Electrical Conductivity (A. J. Armstrong)}

Most electrode sections were either cracked or bloated to such an extent that very few samples could be cut that were large and strong enough for electrical measurements. Only 5 anode sections could be used for electrical experiments. Measurements were made on slices $2102\left(88 \mathrm{ZrO}_{2}-12 \mathrm{Y}_{2} \mathrm{O}_{3}\right)$ and $2206\left(82 \mathrm{ZrO}_{2}-18 \mathrm{CeO}_{2}\right)$. The conductivities of these materials after the test differed surprisingly little (5-10\%) from the results obtained on the virgin samples.

\section{Radiographs of Electrodes and Lead-outs (E. N. Farabaugh)}

In contact radiography, the image contrast is due entirely to the variation in $x$-ray absorption from point-to-point in the specimen. Distinguishing specific features in the radiograph depends on the relative contrast and thus on the differential absorption of x-rays in materials of differing density and atomic constitution. This method of characterization requires only an $\mathbf{x}$-ray source and an emulsion to record the image.

The accompanying radiographs (Figure 3) were taken using an uncolliminated beam of $x$-rays from a tungsten rotating anode operating at $200 \mathrm{kv}$. This high voltage source allowed the viewing of the thick anode and cathode electrodes in transmission. The images were recorded directly on type 57 polaroid film. The specimen-to-source and specimen-to-film distances were 

$20 \mathrm{~cm}$ and $2 \mathrm{~cm}$ respectively. In the radiographs, the exact shape of the electrode is not always recorded. This is due to the geometry of the experimental arrangement and the size of the $x$-ray source. However, the important features, the breaks in the platinum leads, are always easily detected.

In the series of radiographs of the anode side, breaks are seen in A2-7, A2-8, A4-15 and A5-17. (See Figure 3). These electrodes were noted as opening up during the test run. On the cathode side, Cl-1, Cl-4, C3-9, C4-15, and C4-16 are seen to be discontinuous. Of the cathode elements, C1-1 and $4-16$ were noted to have opened during the test. The anode-cathode pair 15 also showed open circuit during operation. Apparently, discontinuities occurred in both the anode and the cathode Pt-wires. C3-9 behaved erratically, but never opened up completely during the test. Cl-4 served as a position of an optical. sight port; it shows no lead in the radiograph.

The overall conclusions are:

I. The leads melted due to excessive Joule heating and were not chemically attacked.

II. The leads should be of sufficient size to carry the current, be thoroughly embedded in the cement, and be securely attached to the ceramic tube (to prevent damage by twisting). 

POST-TEST PHASE COIPOSITION (X-RAY ANALYSIS) FOR CATHODE MATERIALS
InItlal Bulk
Relative Position
of Material Analyzed
Results
aposition (mol \%)
Phases Present and Comments $1 /$

$\because 2 \mathrm{rO}_{2}: 18 \mathrm{CeO}_{2}$

1205

en Circult

1206

$.25 \mathrm{~A} / \mathrm{cm}^{2}$

$12 \mathrm{rO}_{2}: 50 \mathrm{CeO}_{2}$

1312

ppen Circuit.

$502 \mathrm{rO}_{2}: 50 \mathrm{CeO}_{2}$

$1: 307$

..25 $\mathrm{A} / \mathrm{cc}^{2}$

$252 \mathrm{rO}_{2}: 75 \mathrm{CeO}_{2}$

1414

, $5 \mathrm{~A} / \mathrm{cm}^{2}$

$252 \mathrm{rO}_{2}: 75 \mathrm{CeO}_{2}$

11616

$\therefore .25 \mathrm{~A} / \mathrm{cm}^{2}$ upper 1-2 mo white naterial

white surface

yellow Interfor zone

yellow, olfve-green bottom

white zone, top

yellowish interior $z$ ane plus small portion of white zone

yellowish interior zone plus yellow-green bottom zone

yellow-green bottom zone

yellow interior

yellow-green bottom

top white zone + yellow zone

yellowish interior

yellowish-green bottom

white (top) zone

yellow-brown bottom

dark yellow botcom

white (top) zone

white + yellowish zones

yellow-green bottom
Nearly pure mono $\mathrm{ZrO}_{2}+$ f.c.c. solid-solution + cublc and/or tetragonal solid-solution

Mono $\mathrm{ZrO}_{2}+$ poorly crystalline f.c.c. and/or tet solid-solutions

Mono $\mathrm{ZrO}_{2}$ (strong) $+\left(C_{1}\right)$, (strong), + a trace phase ( $P$ )

Mono $\mathrm{ZrO}_{2}+(\mathrm{P})$-Phase (very strong)

Mono $\mathrm{ZrO}_{2}+$ two or more f.c.c. solid-solution phases

Mono $\mathrm{ZrO}_{2}+$ strong $\left(C_{1}\right)$-phase, a $=5.26 \mathrm{~A}$

Mono $\mathrm{ZrO}_{2}+\left(\mathrm{C}_{1}\right)$-phase $+(\mathrm{P})$-phase

(P)-phase strong + Mono $2 \mathrm{rO}_{2}+\left(C_{1}\right)$

Almost pure $\left(C_{1}\right)$-phase $\underline{a}=5.26 \mathrm{~A}+$ trace mono $\mathrm{ZrO}_{2}$

$\left(C_{1}\right)$-phase strong + additional cujic phases with stmilar but slightly larger a + trace (P)-phase

$\left(C_{1}\right)$-phase, + cubic solid-solution, + trace of a third cubic phase

Nearly pure $\left(C_{1}\right)$-phase, $(a=5.26 \AA)+$ traces of thono $\mathrm{ZrO}_{2}$ and a second cubic phase

$(P)$-phase (very strong) $+\left(C_{2}\right) a=5.38 \mathrm{~A}$ phase (strong) + small amount $\left(C_{1}\right)$-phase

Two f.c.c. solld-solutions. Major phase, $\underline{a}=5.35 \mathrm{~A}$; minor phase has larger a

Two f.c.c. phases. Major phase $a=5.38 \mathrm{~A}$, nearly that for pure $\mathrm{CeO}_{2} \quad(\underline{a}=5.42)(P)$-phase also present At least three cubic phases. Major phase $\underline{a}=5.34 \mathrm{~A}$

f.c.c. B25.34-5.35A + f.c.c. with slightly smaller $\underline{a}$ At least three cub1c phases

At least three cubic phases $+(P)$-phase. Major phase has $\underset{\sim}{\sim} 5.38 \mathrm{~A}$ (similar to pure $\mathrm{CeO}_{2}$ ) - lallar to pure $\mathrm{CeO}_{2}$; f.c.c. - face center cublc (Fluortte); Tet = Tetragonal; Mono - Monoclinic.

MOTE: Compare resules (phase assemblages and cell dimensions) with that given in Table 3 to assess change in otarting materials. Color changes are indicative of chemical changes. 

Itlal Bulk aposition (mol \%)
Relative Posttion of Materlal Analyzed
Results

Phases Present and Comments
$\mathrm{CeO}_{2}: 202 \mathrm{rO}_{2}$ :

$\therefore \mathrm{a}_{2} \mathrm{O}_{5}$

.520

gen Circuit

$\mathrm{CeO}_{2}: 2{\mathrm{OZ} \mathrm{rO}_{2}}_{2}$ :

$\mathrm{Ta}_{2} \mathrm{O}_{5}$

is17

$25 \mathrm{~A} / \mathrm{cm}^{2}$

$32 \mathrm{rO}_{2}: 12 \mathrm{Y}_{2} \mathrm{O}_{3}$

1101

$25 \mathrm{~A} / \mathrm{cm}^{2}$

$3 \mathrm{ZrO}_{2}: 12 \mathrm{I}_{2} \mathrm{O}_{3}$

1103

$5 \mathrm{~A} / \mathrm{em}^{2}$ yellow top zone

green bottom

yellow zone upper portion

yellow zone lower portion

bottom zone

bottom, sample near MgO

Insulator

bottom, sample next to $\mathrm{MgO}$ Insulator

white surface
Two dominant cublc phases (å $2.36 \mathrm{~A}$, a $25.28 \mathrm{~A}$ )

Nearly single-phase E.C.C. $\underline{a}=5.35 \mathrm{~A}$

At least two f.c.c. phases. Major phase, $\underline{a}=5.37 \mathrm{~A}$, minor phase has smaller an5.28A

At least three, possibly four cublc phases

E.c.c. $\underline{a}=5.154 \mathrm{~A},+\mathrm{K}_{2} \mathrm{CO}_{3} \cdot \mathrm{nH}_{2} \mathrm{O}$

f.c.c. $+\mathrm{K}_{2} \mathrm{CO}_{3} \cdot \mathrm{nH}_{2} \mathrm{O}$

Two f.c.c. phases plus small amount of mono $\mathrm{ZrO}_{2}$

We11 crystallized f.c.c. phases $\underline{a}=5.145 \mathrm{~A}$ 

Anode Electrode X-ray Results

1. Composition -- $88 \% \mathrm{ZrO}_{2}, 12 \% \mathrm{Y}_{2} \mathrm{O}_{3}$

Original - Very well-crystallized E.c.c., $a=5.151 \AA$

Post Proof Test - Well-crystallized f.c.c., $a=5.136^{\circ}$.

Very slight suggestion of line splitting which could indicate lower symmetry or multiple phases.

Post Phase I Test Samples - bulk material f.c.c., $a=5.15 \AA$

2101

Surface crystallinity good, f.c.c., a $5.14 \AA$.

Intersity varies from original. Line

sharpness varies to suggest splitting in

some directions.

2102

Surface crystallinity good, f.c.c., a $5.14 \AA$

Oriented intensitites. Some peaks show

distinct line splitting.

2103 Similar to 2101. Oriented intensities and

probable line splitting. Approximately

f.c.c., $a=5 \cdot 14 \AA$.

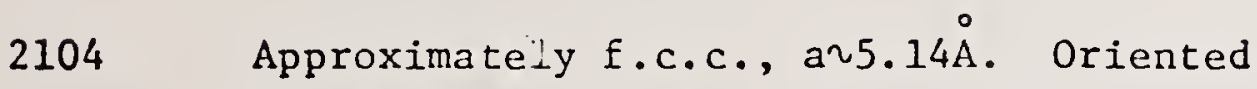

Intensities and some distinct line splitting

Small amount of spinel visible.

2. Composition -- $82 \% \mathrm{ZrO}_{2}, 18 \% \mathrm{CeO}_{2}$

Original - Almost all tetragonal, $a=5.15, c=5.24 \AA$

Post Proof Test - Almost all f.c.c., $a=5.11 \AA^{\circ}$. (Surface)

Post Phase I Test Samples - Crystallinity generally poor although some of the poor resolution may be due to uneven surfaces.

2205-2208 All surface patterns show primarily a cubic (or very nearly cubic) phase with a $5.1 \AA$. They also show monoclinic $\mathrm{ZrO}_{2}$ and spinel (probably $\operatorname{MgAl}_{2} \mathrm{O}_{4}$ ) 

3. Composition -- $50 \% \mathrm{ZrO}_{2}, 50 \% \mathrm{CeO}_{2}$

Original - Primarily tetragonal $(a=5.26, c=5.30 \AA)$ plus a small amount of a cubic phase $(a=5.15 \AA$ ) or tetragonal $(a=5.15, c=5.24 \AA)$ and a trace of a probably cubic phase $(\alpha=5.34 \AA)$.

Post Proof Test - Very poor pattern which is primarily f.c.c., a=5. $12 \AA$.

Post Phase I Test Samples - very poor condition. Only the 2312 sample could be used to obtain a surface pattern. All other patterns were obtained by grinding samples from the top and bottom portions of the electrodes.

2309 Top portion is mostly cubic (or nearly cubic) a=5.26. It also contains small amounts of approximately cubic cells with cell edges of $5.21 \AA$ and $5.16 \AA$ plus a small amount of monoclinic $\mathrm{ZrO}_{2}$.

Bottom portion has three phases present which are similar to the original material: cubic, $a=5.33 \AA$; tetragonal $a=5.27, c=5.31 \AA$; tetragonal $a=5.15, c=5.24 \AA$.

2310 Top portion is mostly nearly cubic (probably tetragonal $a=5.26, c=5.29 \AA$ ) plus small amounts of material with smaller cells ( $\sim 5.21 \AA$, $\sim 5.13 \AA$ ).

Bottom portion is mostly cubic $(a=5.34 \AA)$ plus some tetragonal $(a=5.15, c=5.24 \AA)$.

2311 Top portion is almost all tetragonal ( $a=5.26, c=5.30 \AA$ ) plus a trace of a smaller tetragonal phase $(a=5.15$, $c=5.24 \AA$ ).

Bottom portion is mostly cubic $\left(a=5.34 \AA^{\circ}\right)$ plus some tetragonal ( $a=5.15, c=5.24 \AA$ ). 

The surface is mostly two phases: - cubic $(a=5.14 \AA)$ and tetragonal $(a=5.18, c=5.26 \AA)$. Small amounts of monoclinic $\mathrm{ZrO}_{2}$ and spinel are also visible.

The bulk surface material is primarily cubic (or nearly so) with a $\sim 5.27 \AA$. It also contains smaller amounts of phases with smaller cells with cell edges $\sim 5.21$, $5.16,5.14 \AA$.

4. Composition -- $25 \% \mathrm{ZrO}_{2}, 75 \% \mathrm{CeO}_{2}$

Original - Well crystallized f.c.c., $a=5.342 \mathrm{~A}^{\circ}$

Post Proof Test - Very poorly crystallized mixture of at least three phases of cubic or nearly cubic materials with cells $25.33,5.26$, $5.19 A^{\circ}$ (surface).

Post Phase I Test Samples were considerably fragmented. Surface patterns could be obtained only on the 2413 and 2416 electrodes.

2413 The surface is mostly a cubic phase $(a=5.14 \AA)$. There is also some spinel visible plus traces of monoclinic $\mathrm{ZrO}_{2}$ and a possible cubic $(\mathrm{a}=5.26 \AA)$ phase.

2414 Could not get a useable surface pattern. The ground upper portion is mostly the same as the original material (cubic, $a=5.34 \AA$ ). It also contains small amounts of two other phases: tetragonal, $a=5.23$,

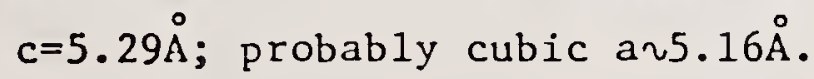

2415 No surface pattern. A loose piece which was mostly surface material was ground for $x$-ray examination. It was mostly cubic with a $5.13 \AA$ plus a small amount of two probably cubic phases, $a=5.22 \AA, a^{\prime}=5.19 \AA$.

2416 Surface pattern is predominantiy cubic (or nearly so) with a 5.2A. Small amounts of a minor cubic component $\left(a^{n}, 5.3 \AA\right)$ and spinel are visible. 
. 
5. Composition -- $20 \% \mathrm{ZrO}_{2}, 78 \% \mathrm{CeO}_{2}, 2 \% \mathrm{Ta}_{2} \mathrm{O}_{5}$

Original - Consists of a major component (well crystallized f.c.c., $a=5.35 \AA$ ) and a minor component (not as well crystallized f.c.c., $a=5.37 \AA$ ).

Post Proof Test - Pattern is nearly cubic, but the crystallinity is only fair. Slight splitting of high angle lines suggest that it may be tetragonal with $a \simeq c \simeq 5.34 \AA$ or two cubics with $\mathrm{a}=5.34 \AA$ and $\mathrm{a}^{\prime}=5.35 \AA$.

Post Phase I Test Samples - All samples have a thin white coating (presumably due to loss of $\mathrm{Ta}$ ) and are green like the original beneath this surface coating. The bulk green material is the well crystallized f.c.c. phase $(a=5.35 \AA$ ).

The white coating, when chipped off and ground, is primarily the f.c.c. phase $(a=5.35 \AA)$ but, also, contains at least two other phases with smaller cubic or nearly cubic cells (a' $25.2 \AA$, a" $25.3 \AA$ ) which are presumably richer in $\mathrm{ZrO}_{2}$.

The surface patterns of all these samples show primarily a poorly crystallized pattern of the $5.2 \AA$ material plus smaller amounts of the $5.3 \AA$ material. Additionally, the surfaces showed:

2517 Traces of spinel and an unidentified material.

2518 Traces of monoclinic $\mathrm{ZrO}_{2}$ and an unidentified material.

2519 No additional phases. 



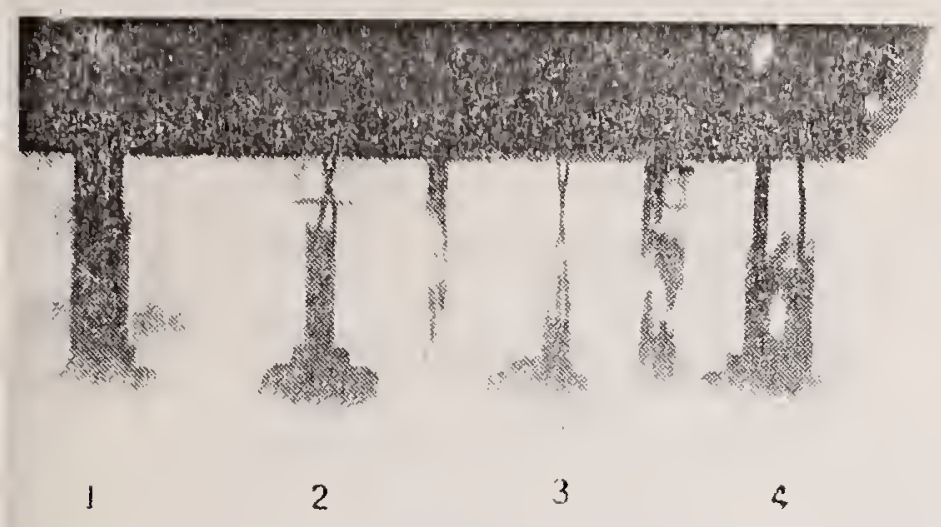

A 1

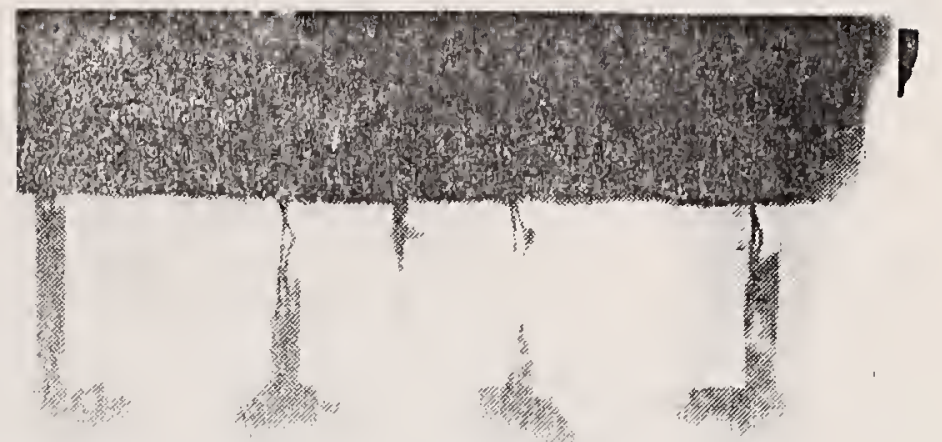

8

A 2
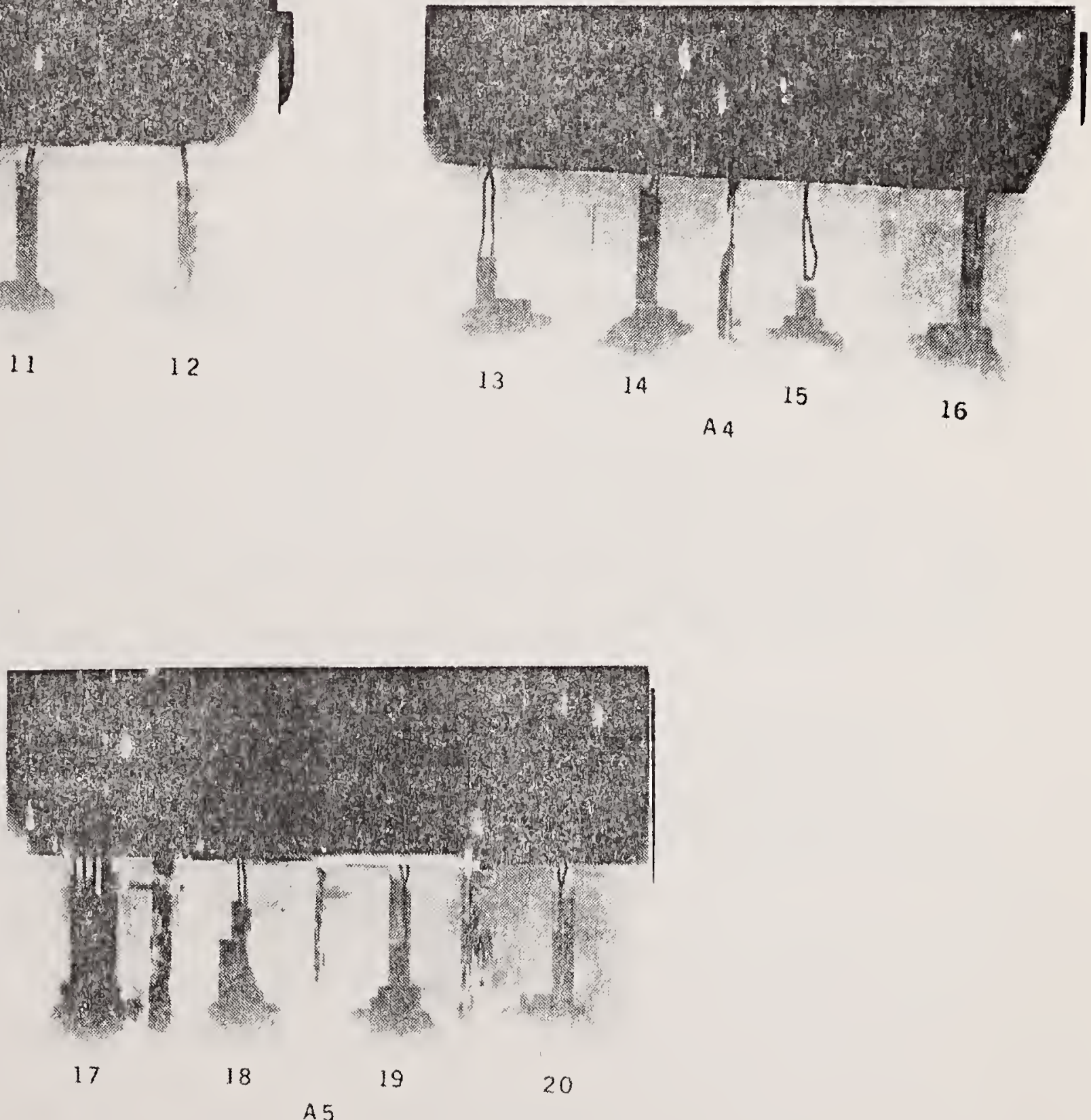

Figure 3. Radiographs of Anode Submodules 1 to 5. 

Task I. OPERATIONAL DESIGIN PROPERTIES

a. VISCOSITY OF COAL SLAGS (W. Capps and D. A. Kauffman)

Reduction-Oxidation Effects on Viscosity

An experiment was conducted to determine if there is a change in viscosity with a change in the oxidation state of iron in coal slag melts.

A slag composition having a moderately high iron content was selected which had been melted previously. K385, containing $40 \%$ by weight of $\mathrm{SiO}_{2}$ ' $15 \% \mathrm{Al}_{2} \mathrm{O}_{3}, 20 \% \mathrm{Fe}_{3} \mathrm{O}_{4}, 17 \% \mathrm{CaO}$, and $8 \% \mathrm{MgO}$, was duplicated and numbered $\mathrm{K} 554$.

It was assumed that the only ions in this synthetic slag that could be shifted easily from one valence state to another were the iron ions. Presumably, by changing the availability of oxygen to the melt, at least some of the iron could be shifted from the divalent state to the trivalent state and back again. It is conceivable that this could affect the viscosity of the slag. If so, the extent of this effect should be known for purposes of slag-wall thickness estimates in operating coal-fired MHD systems.

An alumina tube was used to bubble gases through the melt before and during viscosity determinations. The solid curve in Fig. 4 shows the viscosity-temperature relationship of $\mathrm{k} 385$. This was reported earlier. The melt was exposed to the air in the furnace atmosphere just as all the other melts were that have been described in preceding reports. Figure 4 also shows data points for $\mathrm{k} 554$ with and without bubbling. The data points are numbered in chronological sequence. It is apparent that the two melts, presumably identical in composition, showed similar but not identical viscosity behavior. Points 1 and 2, at about $1530 \mathrm{C}$, show the negligible effect of bubbling with $5 \% \mathrm{H}_{2}$ in argon. Of course, the crucible was open to the air in the furnace and probably there was an abundant supply of oxygen to diffuse into the glass to. counter the reducing effect that the hydrogen may have had. This comparison also holds at $1370 \mathrm{C}$ as shown by the points 3 and 4 which are identical.

When oxygen was bubbled through the melt, however, an increase in viscosity occurred at once. The effect was not large but quite visible. After about $31 / 2$ hours, the viscosity had increased by more than $7 \%$. After bubbling was terminated, the viscosity dropped again but not down to the level before the oxygen bubbling began. 

This experiment was preliminary in nature. The conclusions must necessarily be tentative. One can conclude that the viscosity can be altered by bubbling $\mathrm{O}_{2}$ through the melt. If a reducing atmosphere is desired, it may be necessary to go to greater pains to keep oxygen from the melt surface. It is possible that a covered crucible would permit a greater fluxing effect and be more effective in blocking the counter movement of oxygen back into the molten slag.

This effect will be explored further in the future.

Rebuilding NBS Släg Preparation Facility

After three years the heavy load on the melt furnaces in the Inorganic Glass Section imposed by the MHD viscosity program, along with heavy demands from other programs in progress, finally caused sufficient deterioration to necessitate rebuilding them.

Little melting of new slag compositions was possible during this reporting period.

Accomplishments in refurbishing the melt facilities are as follows:

(1) Two melt furnaces were completely rebuilt with new bricks, a new electrode configuration was designed, and silicon carbide resistance elements were installed.

(2) Ancient and overloaded transformers were replaced by new transformers each having 5 ten-volt increments in their secondary windings.

(3) Phase angle fired, silicon controlled rectifiers, controlled by thermocouple-fed digital proportional controllers, were installed for melt and annealing furnaces.

(4) Digital temperature readout was also provided for melting and annealing furnaces.

This installation is now complete and in oferation and provides a completely modern, stepless control of melting and annealing temperatures.

\section{High Temporature Viscometer}

The high temperat:ure adaptation of the present viscometer is still incomplete. The iridium spindle and crucible have been received. The alumina extension of the iridium spindle has not yet been received. Adaptation to the high temperature graphite furnace is not yet complete. 



\section{Future Plans}

1. An attempt will be made to remelt the Fluidyne Air Heater flyash in an alumina crucible and an alumina spindle will be used to measure the viscosity. This flyash would not make a homogeneous melt and caused disasterous disintegration of the platinum crucible, as reported previously.

2. Bubbling experiments will be resumed in alumina instead of in platinum to permit more strongly reducing atmospheres to be used.

3. High temperature modification of the viscometer will be pursued.

4. An effort will be made to modify the equations developed earlier to include the effect of potassium oxide on the viscosity.

5. A flyash and a bottom ash from Rosebud Coal Seam, as provided by Montana State University, will be melted and their viscosities determined. 



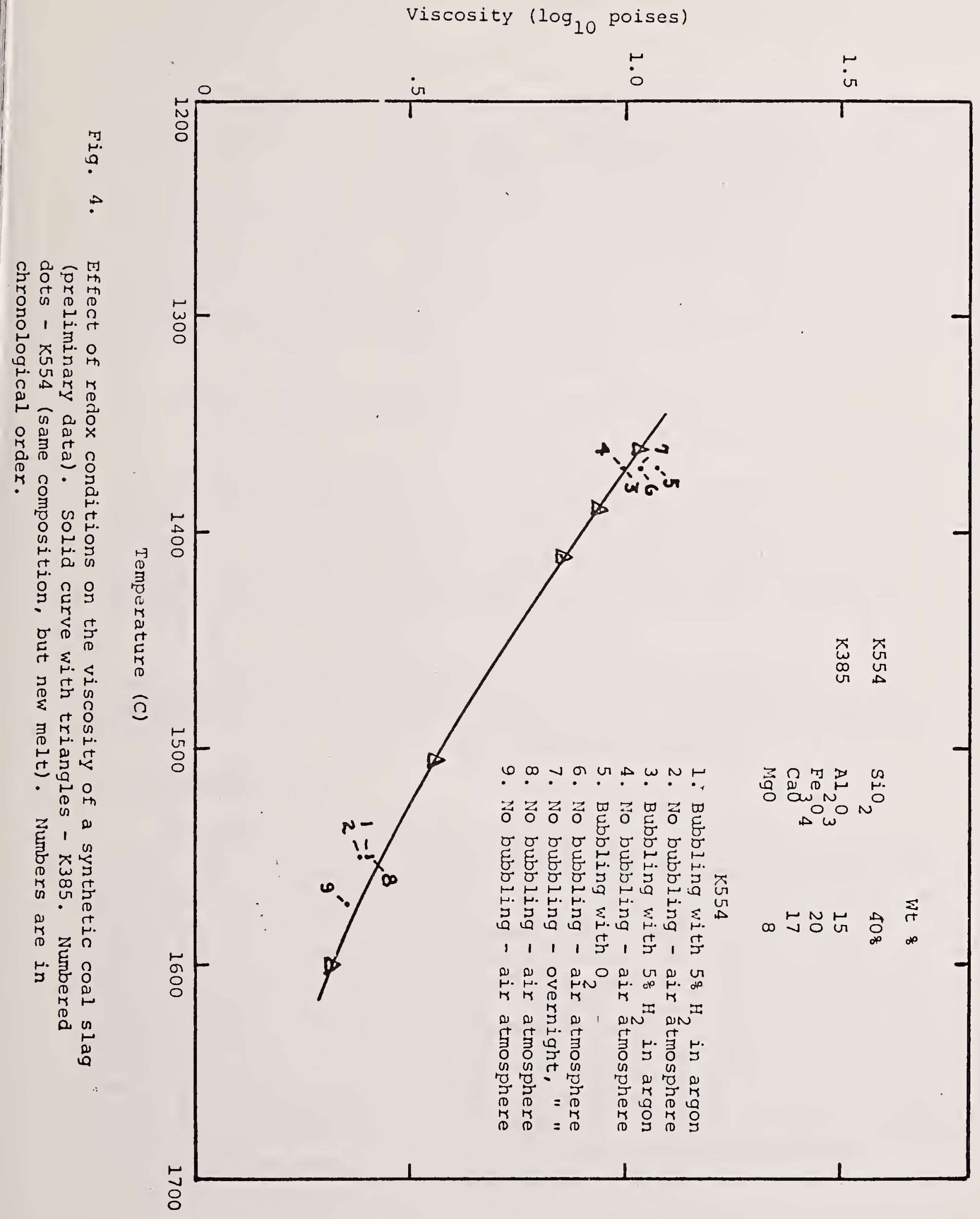



b. Electrical Conductivity (W. R. Hosler, A. J. Armstrong, H. P. R. Frederikse)

Spinels

Solid solutions of $\mathrm{Mg}$-chromite or $\mathrm{Mg}$-aluminate spinels and magnetite $\left(\mathrm{Fe}_{3} \mathrm{O}_{4}\right)$ appear to be promising materials for MHD electrodes. During this reporting period the conductivity of more than a dozen spinels of various $\mathrm{Mg}-\mathrm{Al}-\mathrm{Cr}-\mathrm{Fe}$ ratios were investigated. The sources and compositions of these materials are listed in Table III. Of the group of A. P. Green spinels only the "ISO-C" has sufficient conductivity $\left(\sigma>10^{-2} \mathrm{ohm}^{-1} \mathrm{~cm}^{-1}\right.$ at $\left.1000 \mathrm{~K}\right)$; in the second batch all 5 materials listed are acceptable from this pointof-view. The chromite of the single phase spinels (second group) have somewhat higher conductivities than the aluminates. However, the aluminates are preferable because of their larger corrosion resistance with respect to potassium seed (see discussion under Task J). Fe-Co-spinel appears to have good characteristics as a lead-out material.

A paper discussing "Spinels for MHD-electrodes" will be presented at the 15th Symposium on Engineering Aspects of MHD (May 24-26, 1976, Philadelphia).

Several other spinels of similar composition were sent to NBS by Dr. Rossing (Westinghouse Research Labs). Two of these were Corhart material.s labeled $\mathrm{CClOO}$ and $\mathrm{CClO} 4$ respectively. Their nominal compositions were (in wt. percent): (CClOO! $10 \quad \mathrm{MgO}-10 \mathrm{Al}_{2} \mathrm{O}_{3}-10 \mathrm{Fe}_{2} \mathrm{O}_{3}-70 \quad \mathrm{Cr}_{2} \mathrm{O}_{3}$ and $(\mathrm{CClO4}) \sim 56 \mathrm{MgO}-9 \mathrm{Al}_{2} \mathrm{O}_{3}-10 \mathrm{Fe}_{2} \mathrm{O}_{3}-2 \mathrm{OCr}_{2} \mathrm{O}_{3}$. A third sample prepared by Westinghouse) (SW) was mainly Mg-chromite as indicated by chemical analysis: $10.3 \mathrm{Mg}-50 \mathrm{Cr}-<0.025 \mathrm{Fe}-<0.15 \mathrm{Al}$ (wt. percent).

The electrical conductivities of these three materials are shown in Figure 5. The level of conduction in samples CClO4 and SW is quite high. The Corhart specimens, however, are very porous and inhomogeneous and hence no further studies of these materials were made.

Graded Cermet (UCAR)

The apparatus for measuring the electrical conduction under large temperature gradient conditions has been used to explore the conductivity of a graded ceramic/metal sample furnished by Union Carbide (Parma, OH). This material is used for the wall of jet engines; it is about $1 / 4$ " thick and consists of $\mathrm{Y}$-stabilized zirconia graded with $\mathrm{Ni}$ and $\mathrm{Cr}$ powder from the center of the sample down to nichrome metal at the bottom. Surface temperatures of up to $1800^{\circ} \mathrm{C}$ were established by means of laser heating, while the nichrome metal soldered to a water-cooled copper block was held close to room tumperature. A thermocouple at the interface between the graded oxide $+\mathrm{Ni}+\mathrm{Cr}$ and the stabilized zirconia indicated a temperature of $585^{\circ} \mathrm{C}$. Under these conditions the total resistance of the sandwich was $65 \mathrm{k} \Omega$. The interface temperature could be raised $200-250{ }^{\circ} \mathrm{C}$ to about $800{ }^{\circ} \mathrm{C}$ without danger of $\mathrm{Ni}$ or $\mathrm{Cr}$ oxidation. However, even at that level the zirconia resistanze still is much too higis to permit current transport of the order of 1 to $10 \mathrm{Amp}$. 

IableIII.Composition of Spinel Samples studied

\begin{tabular}{|c|c|c|c|c|c|c|c|c|c|}
\hline & Mgo & $\mathrm{Cr}_{2} \mathrm{O}_{3}$ & $\mathrm{Al}_{2} \mathrm{O}_{3}$ & $\mathrm{Fe}_{2} \mathrm{O}_{3}$ & $\left(\mathrm{Fe}_{3} \mathrm{O}_{4}\right)$ & $\mathrm{Co}_{3} \mathrm{O}_{4}$ & $\mathrm{SiO}_{2}$ & $\mathrm{CaO}$ & porosity (1) \\
\hline${ }^{A} I S O-B 70(w / 0)$ & 70 & 11.7 & 12.0 & 5.3 & & & & & 12.3 \\
\hline sp. $(n / 0)$ & $50+$ & 16.7 & 26.0 & $7 . j$ & & & & & \\
\hline IsO-B50 (w/O) & 50 & 20.1 & 20.0 & 8.8 & & & & & 6.3 \\
\hline sp. $(m / 0)$ & $50+$ & 17.7 & 25.6 & 7.2 & & & & & \\
\hline ISO-B30 (w/O) & 30 & 28.3 & 28.0 & 12.7 & & & & & 20.4 \\
\hline sp. $(\pi / 0)$ & $50+$ & 17.2 & 25.2 & 7.3 & & & & & \\
\hline ISO-C (bio) & 5.8 & 79.3 & 3.14 & 4.8 & & & & & $2-8$ \\
\hline sp. $(m / 0)$ & 50 & $19.8+$ & 28.8 & 20.4 & & & & & \\
\hline${ }_{B-32010}(w / O)$ & 27.0 & 38.7 & 10.4 & 22.8 & & & 0.82 & 0.27 & r. \\
\hline sp. (m/o) & $50+$ & 25.5 & $10.2^{5}$ & 14.2 & & & 0.02 & 4.20 & \\
\hline$b-32260(w / 0)$ & 38 & 31.7 & 10.7 & 18.3 & & & 0.96 & 0.31 & \\
\hline sp. $(m / 0)$ & 50 & 24.0 & 12.5 & 11.5 & & & & & \\
\hline - Chromite \#2 (m/o) & $\begin{array}{r}42.1_{5} \\
144.4^{5}\end{array}$ & $\begin{array}{l}42.15 \\
44.4^{5}\end{array}$ & & 15.8 & 11.11 & & & & \\
\hline - Chramite $\| 6(\mathrm{~m} / 0)$ & 36.4 & 36.4 & & $27.2^{\prime}$ & & & & & \\
\hline & 140.0 & 10.0 & & & 20.01 & & & & \\
\hline - Nluminate \#3 (m/0) & $\frac{42.1}{\left(44.4^{5}\right.}$ & & $\begin{array}{l}42.15 \\
44.4^{5}\end{array}$ & 25.8 & 11.11 & & & & . \\
\hline - Aluminate \#5 (m/o) & $\begin{array}{l}40.0^{5} \\
\left(42.8^{5}\right.\end{array}$ & & $\begin{array}{l}40.0^{5} \\
42.8^{5}\end{array}$ & 20.0 & 14.31 & & & & . \\
\hline - Pe-co spinel (m/O) & & & & & 70.8 & 29.2 & & & \\
\hline
\end{tabular}

- These samples were prepared by the A. P. Green Refractories Companv. The ctemical comcosicion in weign percent is given on the is line of each sample. These scecimens were noz sinale phase, cut a nixture of spinel and excess (cuvis) ::=0 or excess $C=-O$, Isample IJJ-C). The secona line Gives tre comcosltion

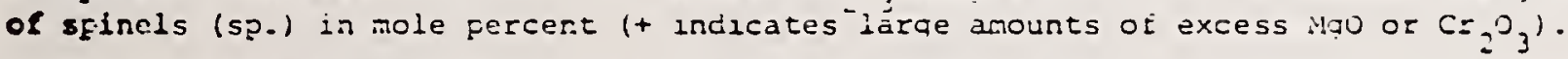

- These samples were prepared in the solid state Chemistry section of Nss. inll jamples were sirgle phase apinel. The fact that the nole persentage of Mgo is smaller enan 50 indicates that these spinels are partially "inversed". 




\section{Vaporization Studies (E. R. Plante)}

The vaporization of $\mathrm{K}(\mathrm{g})+\mathrm{O}_{2}(\mathrm{~g})$ from two synthetic slags, one containing a high $\mathrm{CaO}$ content ( 15 wt. measured using the mass spectrometer - Knudsen effusion method. Pertinent data, results and corclusions will be given in a paper by cook, Plante, Negas, Roth and Olson to be presented at the 15th Symposium on Engineering Aspects of MHD (May 24-26, 1976, Philadelphia). Significantly, both slag samples show higher $K$ pressures than would be expected for "slags" containing only $\mathrm{K}_{2} \mathrm{O} / \mathrm{SiO}_{2}$. This implies that simple seed-slag calculations using pure $\mathrm{K}_{2} \mathrm{O} / \mathrm{SiO}_{2}$ solutions to model the interaction will predict concentrations of $\mathrm{K}_{2} \mathrm{O}$ in the slag solution several times greater than in reality. The high potassium pressures over the CaO-rich slag appear to support the concept that high calcia content in slag will increase the $\mathrm{K}_{2} \mathrm{O}$ activity by reducing the $\mathrm{SiO}_{2}$ activity (hence, less absorption of seed).

Future Work: Measurements of $\mathrm{K}$ pressures over slags of various compositions will be made in an attempt to determine the effects of various components on the activity of $\mathrm{K}_{2} \mathrm{O}$. Vaporization measurements on a pure $\mathrm{K}_{2} \mathrm{O}-\mathrm{SiO}_{2}$ solution will be attempted using smaller orifice size to determine if saturation effects were important in previous measurements. 

a. Spinels (T. Negas, W. R. Hosler)

In the previous suarterly Report the spinel $\mathrm{MgAl}_{2} \mathrm{O}_{4}$ (and $\mathrm{MgO}$ plus $\mathrm{MgAl}_{2} \mathrm{O}_{4}$ ) was shown to have promising resistance to attack by seed. This was based on equilibrium data which demonstrate that $\mathrm{MgAl}_{2} \mathrm{O}_{4}$ does react with $\mathrm{K}_{2} \mathrm{CO}_{3}$ to yield $\mathrm{MgAl}_{2} \mathrm{O}_{4}+\mathrm{MgO}+\mathrm{KAlO}_{2}$ but only very sluggishly. Potassium $B$-alumina cannot be a reaction product unless the ceramic consists of spinel plus $\mathrm{Al}_{2} \mathrm{O}_{3}$ or if Mgo vaporizes preferentially from $\mathrm{MgAl}_{2} \mathrm{O}_{4}$ to drive the bulk composition toward alumina-rich compositions.

The spinel $\mathrm{MgCr}_{2} \mathrm{O}_{4}$ also has been tested with $\mathrm{K}_{2} \mathrm{CO}_{3}$. The composition $\mathrm{MgCr}_{2} \mathrm{O}_{4}: 2 \mathrm{~K}_{2} \mathrm{O}\left(2 \mathrm{~K}_{2} \mathrm{CO}_{3}\right)$ was formulated and fired at $900{ }^{\circ} \mathrm{C}$ in air. Within one hour a liquid phase developed indicating that phase relations were migrating into the $\mathrm{MgO}-\mathrm{Cr}_{2} \mathrm{O}_{3}-\mathrm{K}_{2} \mathrm{O}$-oxygen quaternary. Continued reaction at $900{ }^{\circ} \mathrm{C}, 16$ hours, yields

$$
\mathrm{MgCr}_{2} \mathrm{O}_{4}+2 \mathrm{~K}_{2} \mathrm{O}+11 / 2 \mathrm{O}_{2}+\mathrm{MgO}+2 \mathrm{~K}_{2} \mathrm{CrO}_{4} \ldots \ldots \ldots \ldots
$$

The corrosion product $\mathrm{K}_{2} \mathrm{CrO}_{4}$ melts at $971{ }^{\circ} \mathrm{C}$ and, hence, liquid formation at low temperatures is expected when $\mathrm{MgCr}_{2} \mathrm{O}_{4}$ reacts with seed. It should be noted that reaction ( 1 ) proceeds to the right only when the oxygen activity is high. Meadowcroftl tested $\mathrm{MgCr}_{2} \mathrm{O}_{4}$ by exposing the material to a simulated, seeded, MHD environment at $1620 \mathrm{~K}, 100 \mathrm{hr}$. Results indicated that resistance to seed is extremely poor, the material dissociating to leave only Mgo.

Some of the spinel samples listed below have been exposed to $\mathrm{K}_{2} \mathrm{CO}_{3}$ in a covered Pt-crucible for periods of 4 hours at 800,1000 and $1200{ }^{\circ} \mathrm{C}$. In each case the chromite-spinels were attacked by the potassium forming bright yellow K-chromate. The Mg-Fe-aluminate spinels showed no visible signs of any chemical reaction. Some weight gain occurred due to seed penetration into the pores of the samples, followed by further weight increase when the $\mathrm{K}_{2} \mathrm{CO}_{3}$ hydrated during storage in the laboratory.

Six spinels were prepared based on the chemical considerations outlined in the December 1975 guarterly Report. These materials are single phase spinel solid solutions prepared at elevated temperatures from the following initial bulk compositions:
1) $2 \mathrm{MgCr}_{2} \mathrm{O}_{4}: 1 / 2 \mathrm{Fe}_{3} \mathrm{O}_{4}$
2) $2 \mathrm{MgCr}_{2} \mathrm{O}_{4}: \mathrm{Fe}_{3} \mathrm{O}_{4}$
3) $\mathrm{MgAl}_{2} \mathrm{O}_{4}: \mathrm{Fe}_{3} \mathrm{O}_{4}$
4) $2 \mathrm{MgAl}_{2} \mathrm{O}_{4}: 1 / 2 \mathrm{Fe}_{3} \mathrm{O}_{4}$
5) $3 \mathrm{MgAl}_{2} \mathrm{O}_{4}: \mathrm{Fe}_{3} \mathrm{O}_{4}$
6) $70\left(w t_{8}\right) \mathrm{Fe}_{3} \mathrm{O}_{4}: 30 \mathrm{Co}_{3} \mathrm{O}_{4}$

The electrical conductivities of all of these materials have been measured (see Task I). Composition (5) appears attractive from the standpoint of a) suitable conductivity, b) low iron oxide content and c) high melting point $\left(>1750{ }^{\circ} \mathrm{C}\right.$, in air). Composition (6) offers resistance to oxidation at low 

temperatures and high oxygen potential but is less refractory. Hence, it could be used within the lower temperature portions of an electrode module graded with, for example, composition (5).

The compatibility of $\mathrm{LaCrO}_{3}$, another lead-out candidate, with $\mathrm{MgCr}_{2} \mathrm{O}_{4}$ spinel was demonstrated by firing the composition $\mathrm{LaCrO}_{3}: \mathrm{MgCr}_{2} \mathrm{O}_{4}$ at $1400^{\circ} \mathrm{C}$ and $1500{ }^{\circ} \mathrm{C}, 3$ days. No reaction was observed in accord with ${ }^{2}$ the results of Dr. B. Rossing, Westinghouse Corp: ${ }^{2}$ Additionally, Mgo (insulator) does not react with $\mathrm{LaCrO}_{3}$ as evidenced by firing the composition, $\mathrm{MgO}: 2 \mathrm{LaCrO}_{3}$, $1500{ }^{\circ} \mathrm{C}, 5$ days. No reaction was observed. These data indicate that an electrode module composed of $\mathrm{MgO}$ (insulator) - $\mathrm{LaCrO}_{3}$ (lead-out) - $\mathrm{MgCr}_{2} \mathrm{O}_{4}$ (hicher temperature portion of an electrode) represents a compatible phase assemblage. It appenrs likely that this relationship should hold for spinels other than $\mathrm{MgCr}_{2} \mathrm{O}_{4}$.

\section{References}

1. D. B. Meadowcroft, Energy Conversion $\underline{8}, 185$ (1968).

2. Dr. B. Rossing, personal communication.

b. SEM and EDX Characterization of Corhart X-317 Refractory Ceramics (spinels) Tested at Fluidyne Eng. Corp. (E. N. Farabaugh)

Preliminary characterization of Corhart $\mathrm{x}-317,50 \mathrm{MgO}+50 \mathrm{MgAl}_{2} \mathrm{O}_{4}$ (wt. percent) refractory ceramic body, has been undertaken to determine elemental distribution near the slag-refractory interface and also in the bulk of the refractory.

Figure $6 a$ is a $16 \mathrm{X}$ SEM micrograph of a section of specimen $F N-27$, material \#39, lot Corhart X-317, and test No. 53, $1800 \mathrm{~K}$ for 30 hours. The area on the left of the micrograph that is porous looking is the edge of the specimen that had direct exposure to the slag. The boundary of the slag layer is defined by the boundary between the porous material (slag) and the more dense appearing material (refractory).

Figure $6 \mathrm{~b}$ is a $\mathrm{Si}$ map of the same area at the same magnification. The silicon rich slag layer is sharply outlined at this magnification. There is evidence of some $\mathrm{Si}$ in the refractory also. Ca and $\mathrm{Mg}$ maps are shown in Figures $6 \mathrm{c}$ and $6 \mathrm{~d}$. Ag.lin a rather sharp boundary between the slag and the refractory is revealed. Maps for $\mathrm{K}, \mathrm{Fe}$, and $\mathrm{Al}$ were also taken. These indicated $\mathrm{K}$ present in both slag and refractory with higher concentration in the slag. Fe was also present in the slag layer. Al was distributed almost uniformiy across the slag and the refractoiy. Examination at higher magnification, to be done at a later time, will determine if any diffusion of the slag constituents into the refractory has occurred.

Figure 7 a shows a SEM micrograph of one of the edges of the specimen which was not directly exposed to the slag. Figure $7 \mathrm{~b}$ is a si map of the same area at the same magnification. Comparing Fig. $6 \mathrm{~b}$ and Fig. $7 \mathrm{~b}$ it is noted that the uniform Si distribution in Fig. $6 \mathrm{~b}$ is due to a uniformly thick slag layer a.d the uneven thickness of $\mathrm{Si}$ in $\mathrm{Fig}$. $7 \mathrm{~b}$ is due to an uneven slag layer. The rounding of the corner of the specimen (seen in Figs. $6 \mathrm{~b}, 6 \mathrm{c}$ and $6 \mathrm{~d}$ ) must be due to erosion of the specimen and not due to penetration of the $\mathrm{Si}$ and $\mathrm{Ca}$ into the refractory to give the appearance of a rounded corner. The $\mathrm{Mg}$ map also indicates that some of the refractory 



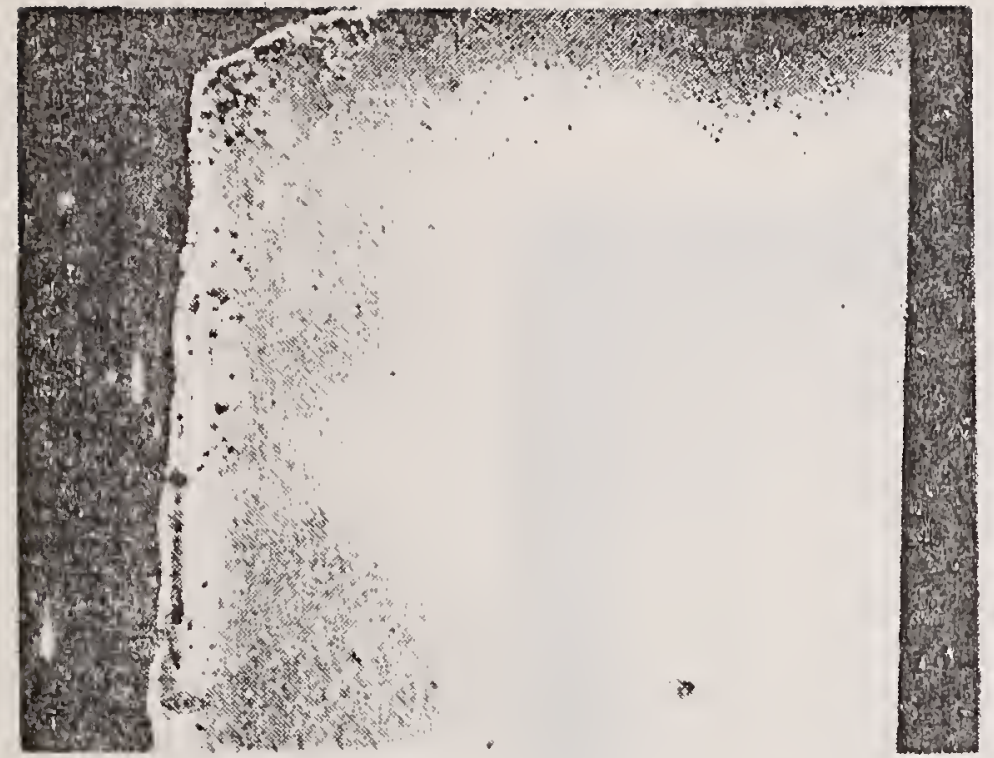

Fig. 5a. $16 \times$ SEM micrograph \#FN-27 corhart $\mathrm{x}-317$.

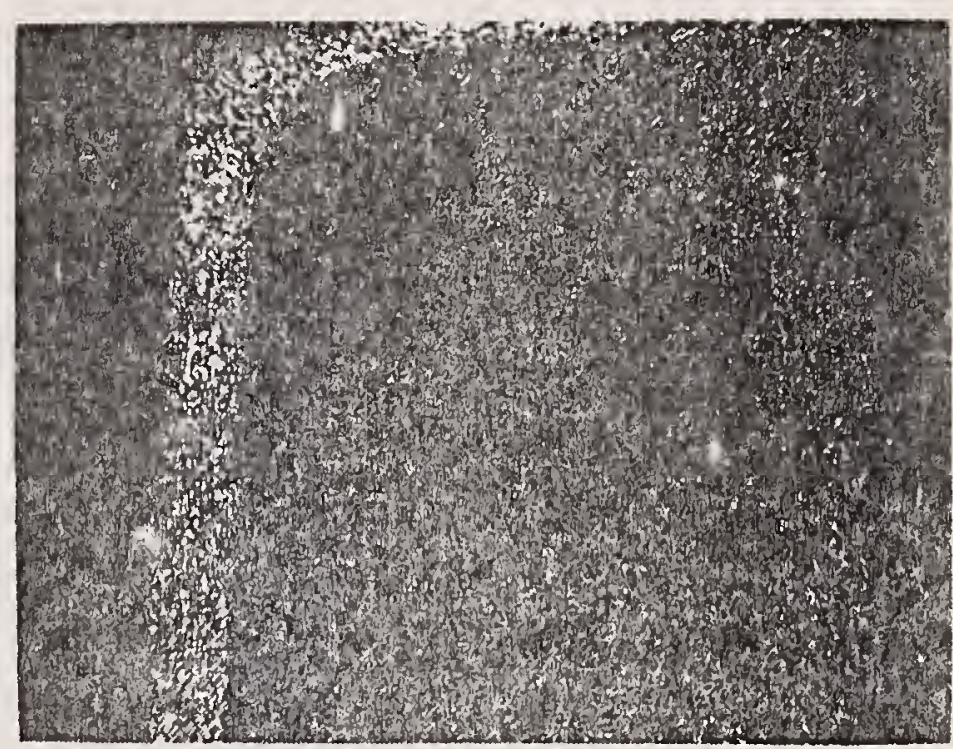

Fig. 6b. Sil lap of the Same Area Showing the S.lag Layer Refractory Boundary.

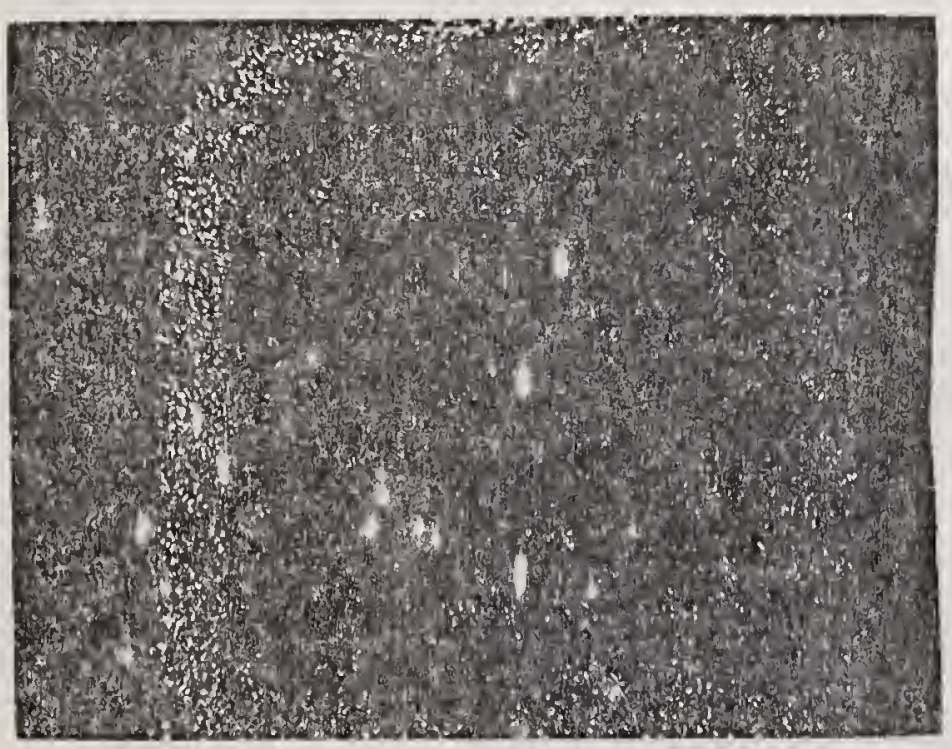

Fig. 6c. Ca Map of the Same Area Also Showing the Slag Layer Refractory Boundary.

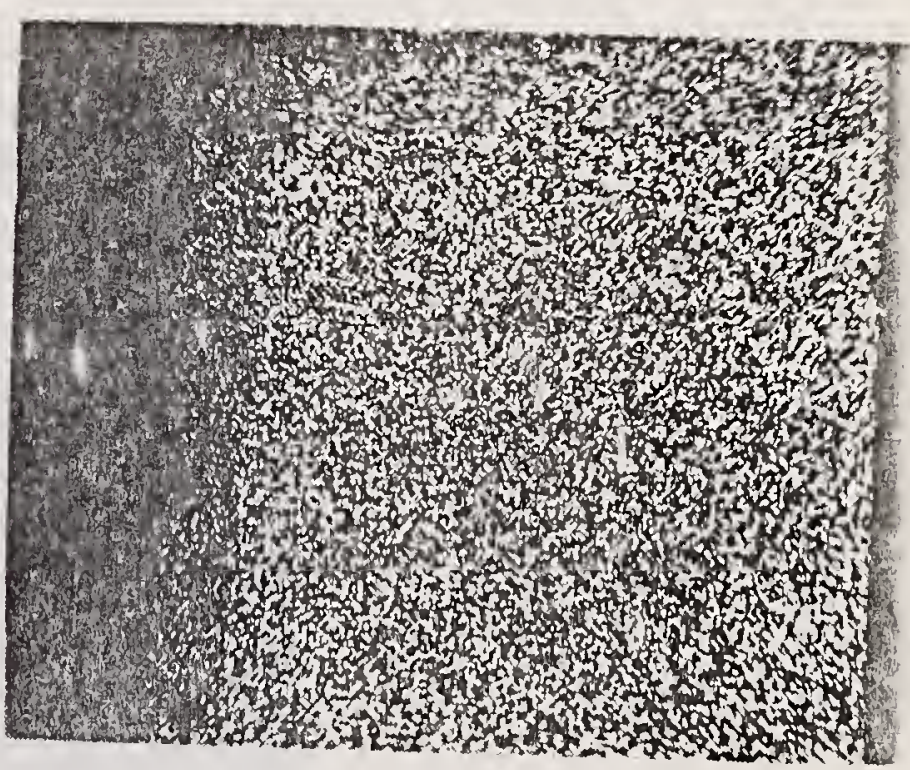

Fig. 6d. Mg Map of the Same Area Showing the Same Slag Laye? Refractory Boundary. 



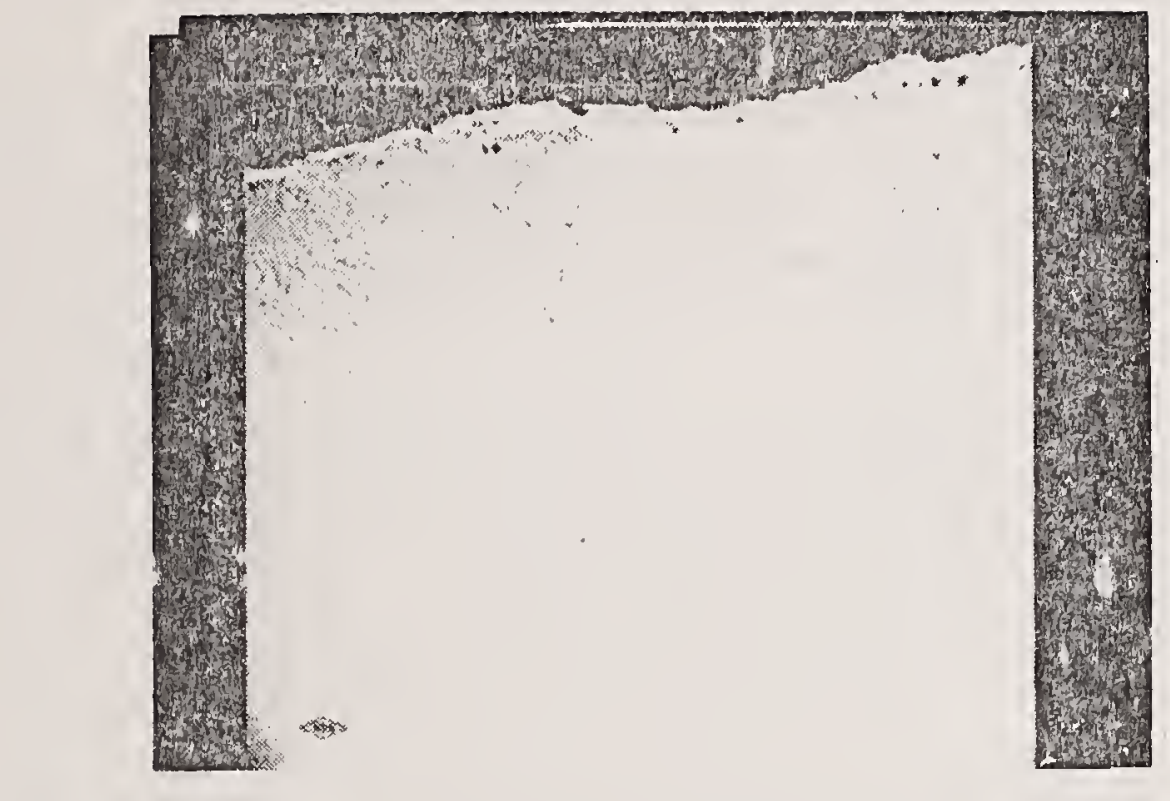

Fig. 7a. 16X SEM Micrograph of one of the Edges of the specimen which was not Directly Exposed to the Slag.

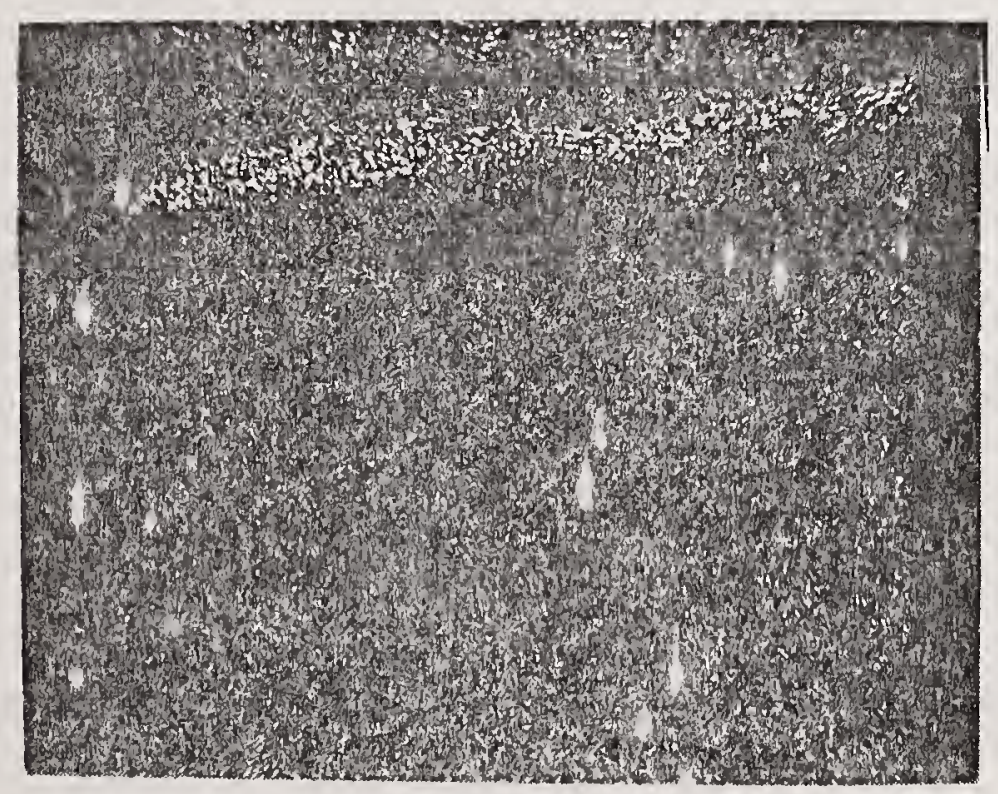

Fig.71. Si Map of the Same Area Showing the Slag Layer Refractory Boundary. 

body has been removed at the corner. fabricated with sharp corners).

(It is assumed that the specimen was

Figure $8 \mathrm{a}(\mathrm{p} .34)$ is a $1600 \mathrm{x}$ SEM micrograph taken well away from the slag layer and in the interior of the specimen. Figure $8 \mathrm{~b}$ ( $p .34$ ) is an EDX spectrum of the same area. The predominate lines indicate the prensence of $\mathrm{Mg}, \mathrm{Al}$, (the two strongest peaks) $\mathrm{Ca}$, and quite small amounts of $\mathrm{Cl}$ and $\mathrm{Si}$. It is felt that the $\mathrm{Ca}, \mathrm{Cl}$, and $\mathrm{Si}$ detected must be present as additives to the refractory and not due to any diffused material.

Figure $9 a(p .34)$ is a $1600 x$ SEM mic ograph taken in the slag layer. There isn't a great difference in the appearance of the slag surface and the refractory surface. It is possible that polishing and etching these surfaces would bring out different surface features. Figure $9 \mathrm{~b}$ (p. 34) is an EDX spectrum of the same area. Note now we have three strong peaks, Mg, Al, and $\mathrm{Si}$ and many smaller peaks. The other elements in the slag are $\mathrm{S}, \mathrm{Cl}$, $\mathrm{K}, \mathrm{Ca}, \mathrm{Ti}, \mathrm{Cr}$ and $\mathrm{Fe}$.

This work will continue and data will be taken to determine if any elemental concentration gradients exist in the slag or the refractory. Areas surrounding cracks and large pores in the refractory will be examined to determine if they have provided an easy path for elemental diffusion.

\section{Diffusion (E. N. Farabaugh, J. R. Manning)}

Work has continued on the study of the penetration of $\mathrm{K}$ into materials used in the MHD process. Previously, a diffusion couple of ceramic $\mathrm{Al}_{2} \mathrm{O}_{3}$ embedded in $\mathrm{B}-\mathrm{Al}_{2} \mathrm{O}_{3}$ was heated at $1400{ }^{\circ} \mathrm{C}$ for 92 hours and the results reported. Since the last reporting period, two more couples have been made. Couple \#2 was again ceramic $\mathrm{Al}_{2} \mathrm{O}_{3}$ embedded in $\mathrm{B}-\mathrm{Al}_{2} \mathrm{O}_{3}$. This couple was heated at $1400{ }^{\circ} \mathrm{C}$ for 24 hours. Couple \#3 was ceramic Mgo (85\% dense) embedded in $\mathrm{B}-\mathrm{Al}_{2} \mathrm{O}_{3}$. This couple was also heated at $1400{ }^{\circ} \mathrm{C}$ for 24 hours.

With this treating time, it was expected that the $\mathrm{K}$ would not pentrate as deeply into the $\mathrm{Al}_{2} \mathrm{O}_{3}$ as it did for the 92 hour run, and that the concentration profiles from opposite edges would not overlap. However, $\mathrm{K}$ maps of the specimen that were taken indicate vanishingly small $\mathrm{K}$ concentrations. Figure 10 (p. 35) shows a $18 X$ SEM secondary electron image micrograph of an edge of couple \#2. Fiaure 11 ( $p .35)$ is a $K$ map of the same area. There is little concentration of $\mathrm{K}$ shown. A point-by-point analysis did show some $\mathrm{K}$ present in a narrow region near the surface. An analysis done at higher magnification will be done in an attempt to pick up any $\mathrm{K}$ gradiert. More $\mathrm{Al}_{2} \mathrm{O}_{3}$ couples will be made at this temperature and time. Concentration profiles will be determined to verify that the $\mathrm{K}$ concentrations are as low as they appear in thıs experiment.

Some time has been spent preparing our laboratories for the arrival of the new SEM and EDX and accessories. With this new equipment on line, it is anticipated that problems encountered in doing EDX analysis with the older available equipment will be eliminated. 



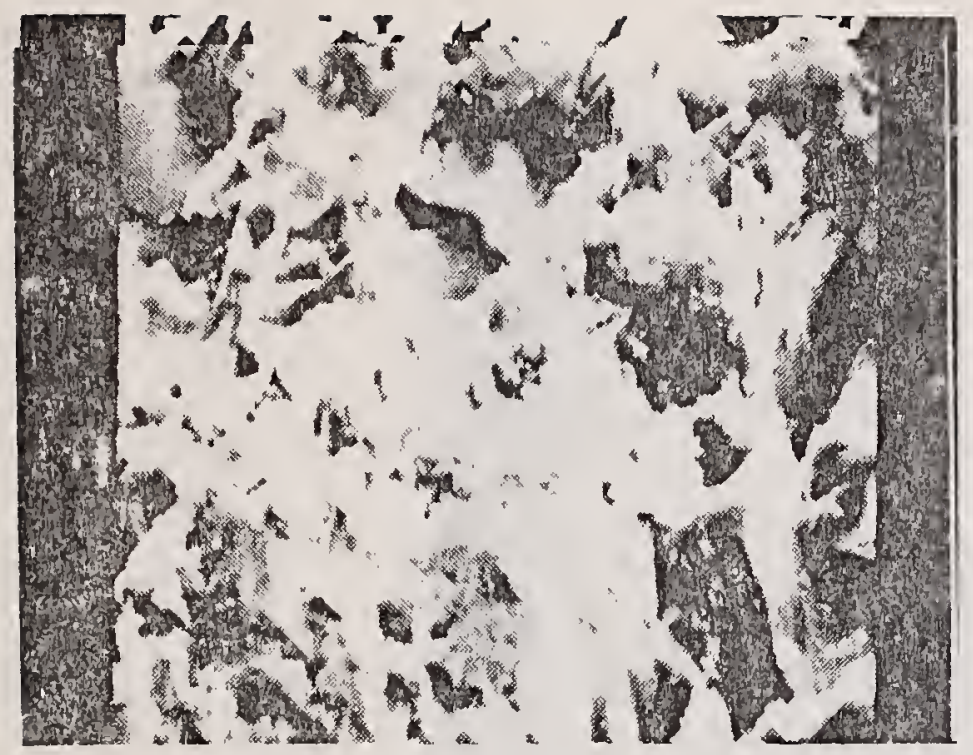

Eig. 8a. 1600X SEM Micrograph Taken Well Away from the Slag Refractory Boundary. (Unpolished Surface).

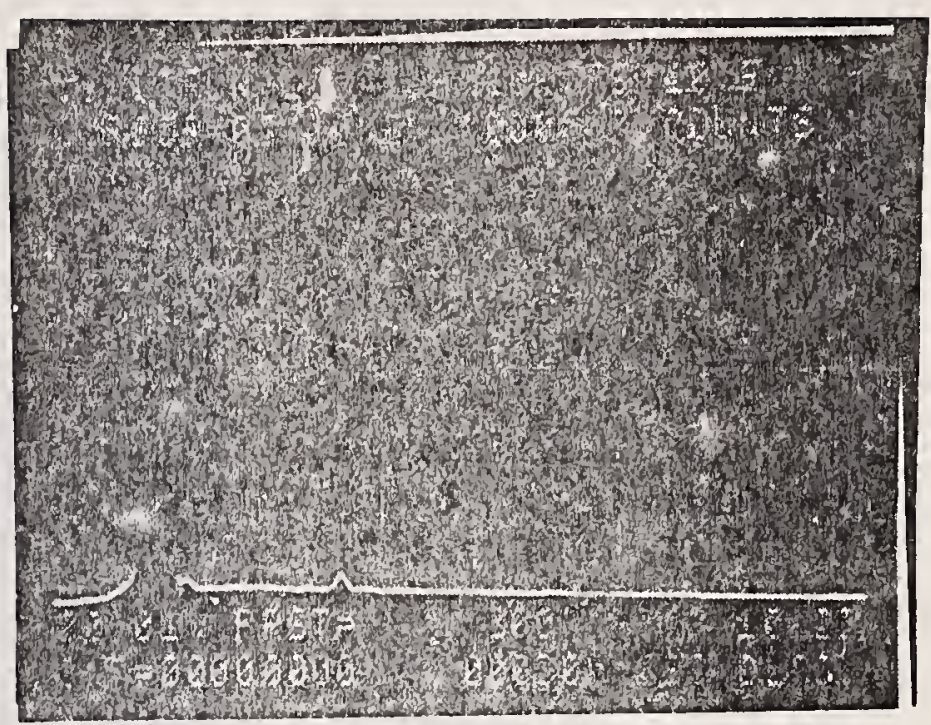

Fig. 8b. FDX Spectrum of the Same Area Shown in the Micrograph. Larg peaks are due to $\mathrm{Mg}$ and $\mathrm{Al}$.

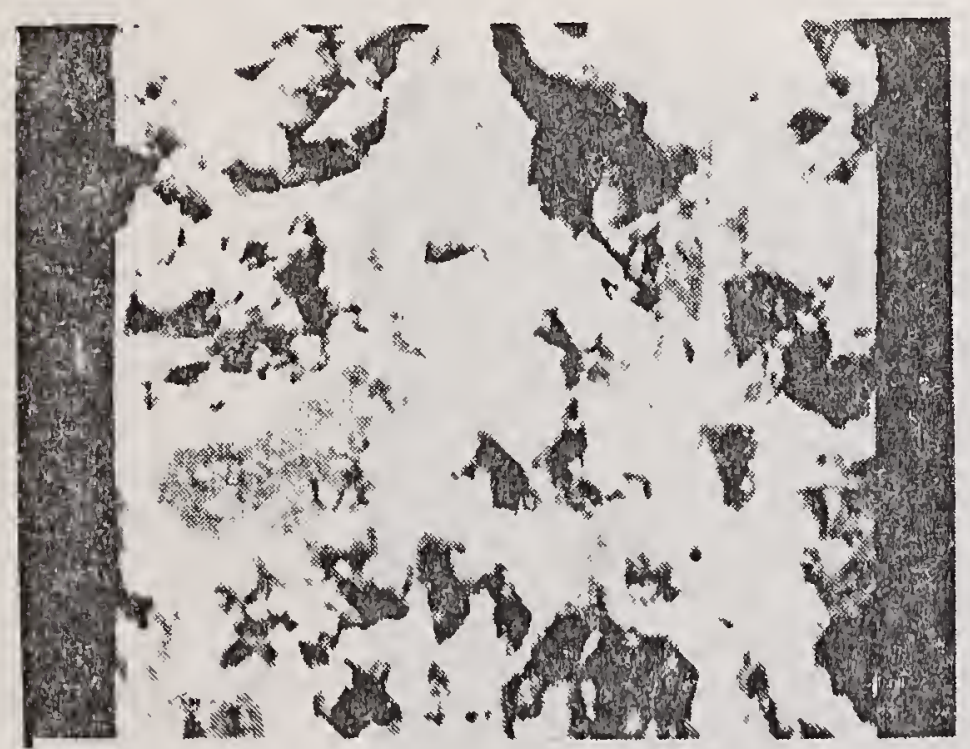

Fig. 9a. 1600X SEM Mıcrograph Taken in the Slag Layer. (Unpolished Surface).

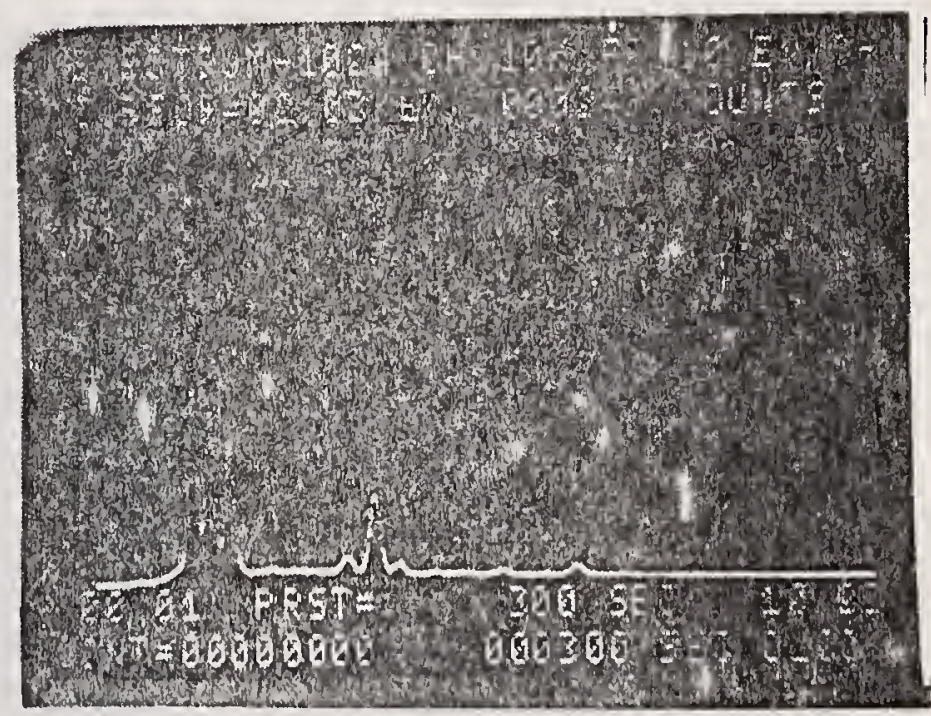

Fig. 9b. EDX Spectrum of the Same Area Shown in the Micrograph. Iarge Peaks are due to $\mathrm{Mg}$, $\triangle \perp$ and $\mathrm{Si}$. 



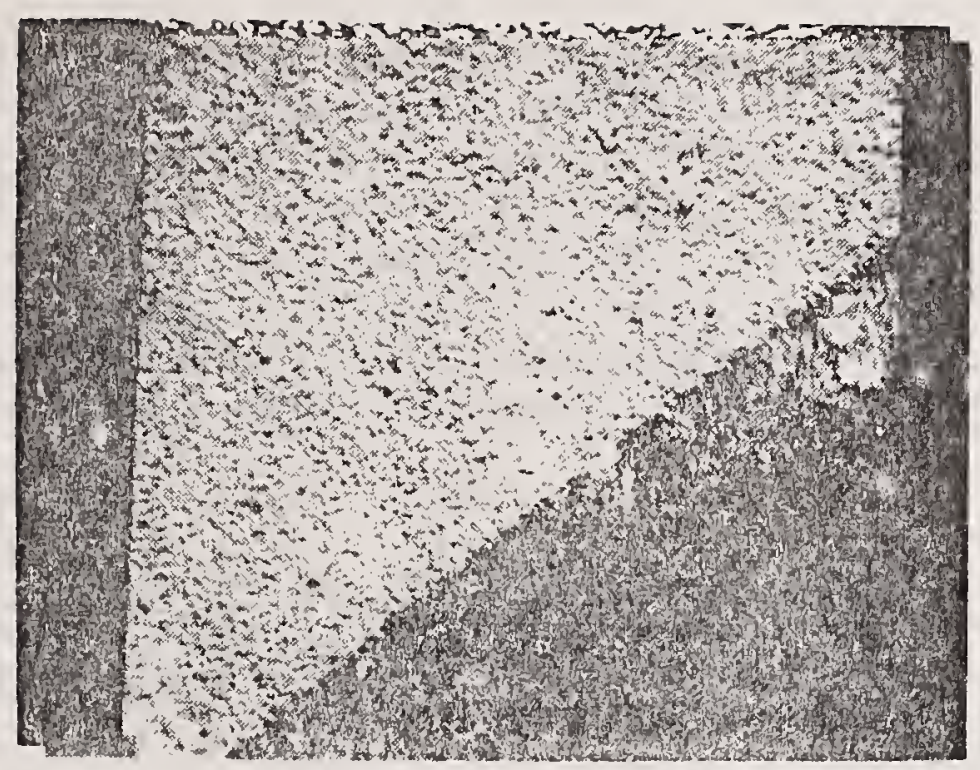

Figure 10. 18x Secondary Electron Image Micrograph of an Edge of $\mathrm{K}$-diffused $\mathrm{Al}_{2} \mathrm{O}_{3}$ Specimen.

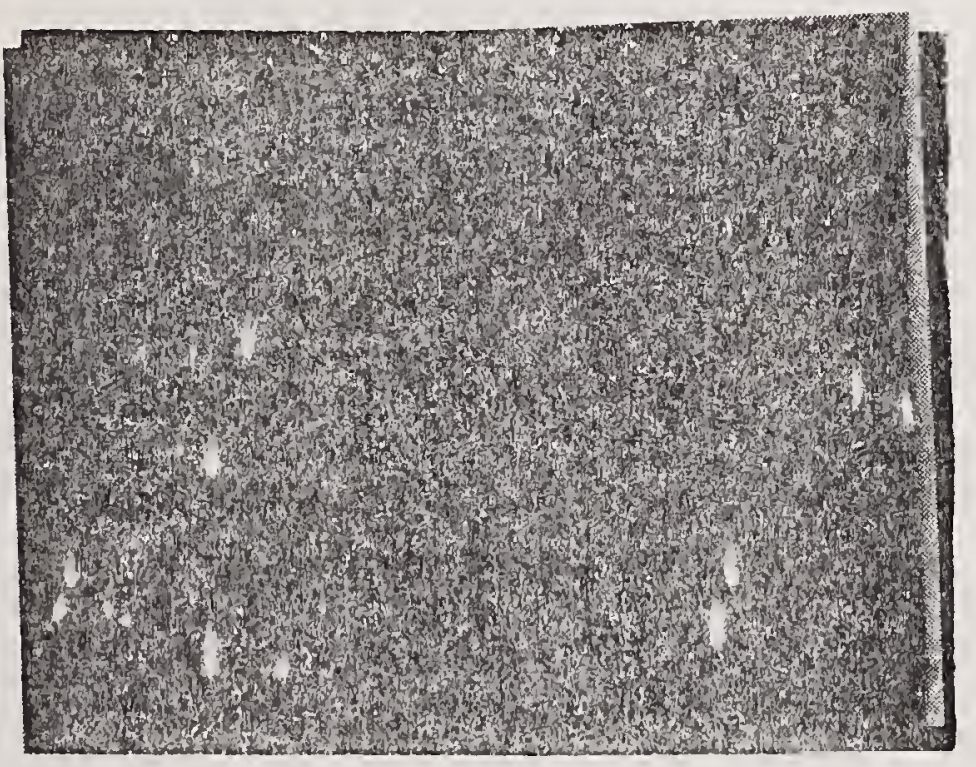

Figure 11. K Map of the Same Area at the Samo Magnification. 

As another part of the present diffusion work, the kinetic diffusion theory necessary to predict how diffusion interactions can influence degradation of MHD materials is being developed. When ions diffuse through regions of material having regular crystal structure, without cracks, pores or similar gross imperfections, kinetic interactions between the different metal ion fluxes taking place on the same sublattice occur. This especially happens when electric fields and temperature gradients bias these fluxes, as customarily is the case in MHD systems. To derive equations describing these interactions, the relation between the non-random diffusion that results from temperature gradients and the non-random diffusion known to arise from correlated ion jumps in isothermal systems is being investigated. It is found that similar parameters enter into both types of non-random calculations.

\section{a. Seed/Slag Interaction (I. Cook)}

The most important factors in determining seed/slag interaction are 1) partial pressure of potassium in the channel, $P_{K}$; 2) temperature at which the interaction takes place; 3) the bulk chemical composition of the unseeded coal ash. Factors 1 and 2 can be calculated, estimated or observed. The composition of coal slag, a chernically complex substance, requires systematic analysis before generalizations suitable for the purposes at hand can be made. As an initial step in this direction, consider the analyses given by Selvig and Gibson (Bureau of Mines, Bull. 567 (1956), Table 2), which show the variability of coal ash in a typical bed of pennsylvania coal. Recalculated, the analyses plot as shown in Figure 12 below, for an assumed $\$ \mathrm{Fe}^{+3} / \mathrm{Fe}^{+2}=0.20$. Si/Al+Fe ratio is nearly constant at $\sim 1.5$. Inspection of other analyses listed in U.S. Bureau of Mines Bulletin 567 shows that the above range of analyses may be representative. If so, then the studies of seed/slag interaction should concentrate on compositions close to the range shown in Figure $12 \mathrm{CaO}-\mathrm{Al}_{2} \mathrm{O}_{3}-\mathrm{SiO}_{2}$ may thus prove useful as a model system with which to consider the interaction of seed and slag.

As an example of this approach, consider the application of results of quench experiments on $\mathrm{K}_{2} \mathrm{O}-\mathrm{CaO}-\mathrm{Al}_{2} \mathrm{O}_{3}-\mathrm{SiO}_{2}$ mixtures presented in the previous quarterly report. These results may be used to construct the schematic phase diagram shown in Figure 13 below. The effect of adding CaO to compositions rich in $\mathrm{KAISiO}_{4}$, a compound thought to be responsible for tying up much of the unrecoverable $\mathrm{K}_{2} \mathrm{O}$ in MHD slags, is clear. If $\mathrm{CaO}$ is added so that the bulk composition moves from three-phase filed A through $B$ to $\mathrm{C}, \mathrm{a}_{\mathrm{K}_{2} \mathrm{O}}$ will increase progressively, assuming that a slight excess of component $A_{1} 1_{2} \mathrm{O}_{3}$ is present so that $\mathrm{a}_{\mathrm{K}_{2} \mathrm{O}}$ is buffered. If $\mathrm{a}_{\mathrm{K}_{2} \mathrm{O}}$ is increased by addition of $\mathrm{CaO}$, then $\mathrm{P}_{\mathrm{K}}$ must be increased as well, meaning that for a given $A l / S i$ ratjo addition of $\mathrm{CaO}$ is likely to result in decreased $\mathrm{K}_{2} \mathrm{O}$ absorption by the coal slag. Whether this is true in general, must of ${ }^{2}$ course be tested by experiments. It is likely that FeO and MgO have similar effects upon $\mathrm{a}_{\mathrm{K}_{2} \mathrm{O}}$ since they are chemically similar, and because all are capable of substitution for each other to a large degree in silicate phases.

Further studies of seed/slag interaction will concentrate on determining, for a reasonable range of idealized coal slag compositions, the equilibrium phase assemblages that result when $\mathrm{k}_{2} \mathrm{O}$ is added. This equilibrium data will allow more detailed frediction of seed/slag interaction under channel conditions. Preliminary indications are that the phase equilibrium data, when analyzed and presented in terms of the chemical potential of $\mathrm{K}_{2} \mathrm{O}, \mu_{\mathrm{K}_{2} \mathrm{O}}$, give a clearer visualization of seed/slag interaction than do conventional diagrams. Given in this way, the data also allow direct correlation with vaporization data. 



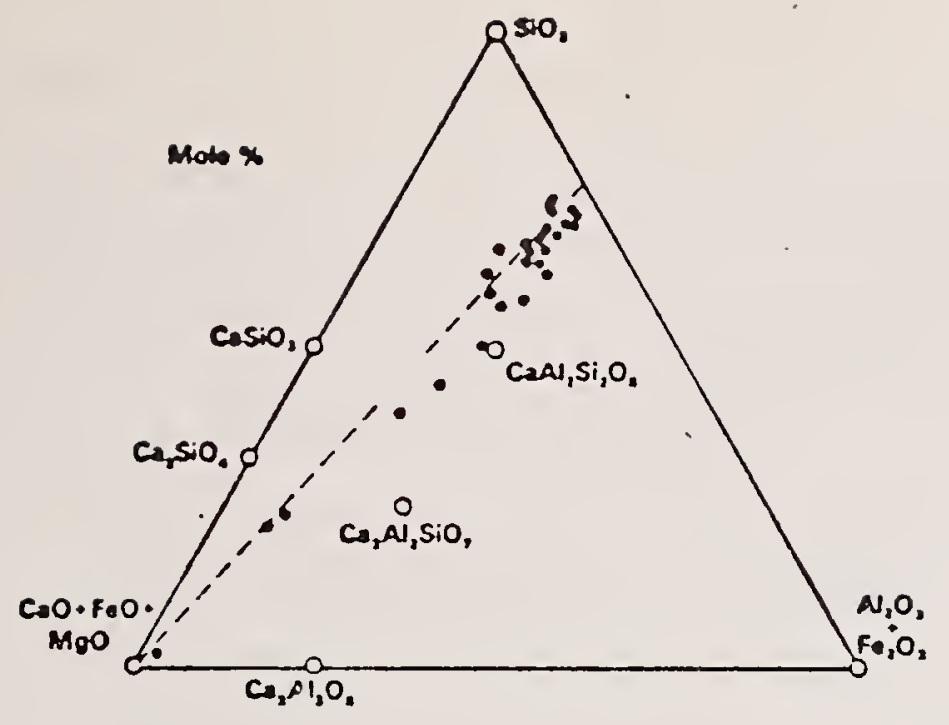

Figurc 12 Recalculatad analyses of coal ash from Pennsylvania coal (dots), sncwn in relation to compounds in the system $\mathrm{CaO}-\mathrm{Al}_{2} \mathrm{O}_{3}-\mathrm{SiO}_{2}$ (oocn

circles). Dashed line shows $\mathrm{Si} /\left(\mathrm{Al}+\mathrm{Fe}^{+3}\right)=1.5$.

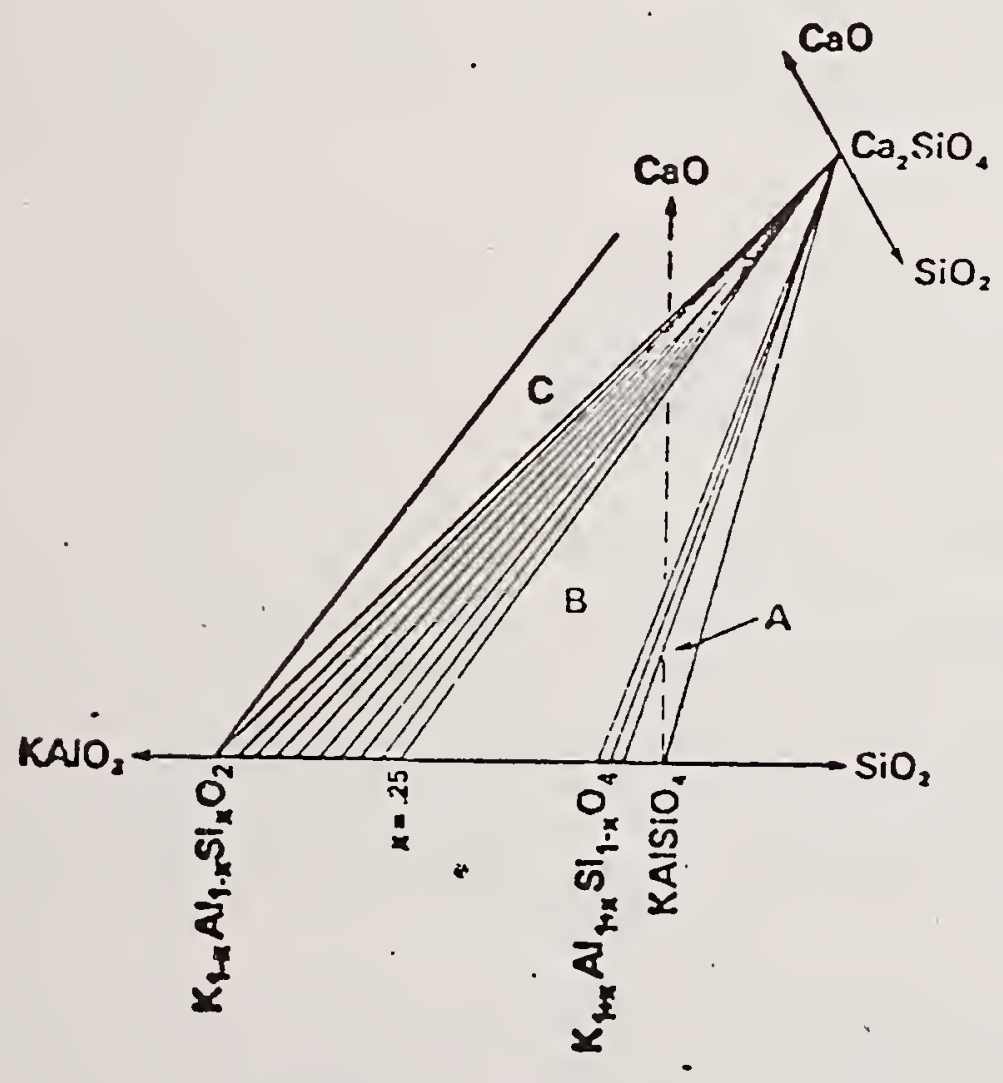

Flgure 13 Effect of adding CaO. to compositiotis rlch in $\mathrm{KHSiO}_{4}$ and near the temary plane $\mathrm{NH}_{2} \mathrm{O}_{2}$ $\mathrm{SHO}_{2}-\mathrm{CaO}$. 



\section{e. Seed Regeneration ( $P$. Skarstad)}

Spent seed in the form of potassium sulfate can be separated from the insoluble portion of coal ash by extraction with water. The sulfate may then be removed from solution and replaced by an anion suitable for recycling into the combustor. Sulfate can be precipitated with Group II cations, the most readily available of which is calcium. Choice of anion involves the following consideration:

1. The anion should not contain elements which form undesirable combustion products, e.g. halogens, sulfur.

2. It should be inexpensive and readily available in large quantities.

3. Both the calcium and potassium salfs should be much more soluble in water than calcium sulfate $\left(\mathrm{K}_{\mathrm{sp}}^{20^{8}}=2 \times 10^{-4}\right)$.

4. Hydrolysis should occur to a small extent. In other words the anion should be the conjugate base of a reasonably strong acid consistent with requirements $1-3$.

The anions of certain common industrial organic acids seem to fulfil all four criteria. Formate appears to be the best of these based on availability, solubility of the final potassium salt, process flexibility, and recovery efficiency. Thus, a version of the "Formate Process", used commercially for conversion of $\mathrm{K}_{2} \mathrm{SO}_{4}$ to $\mathrm{K}_{2} \mathrm{CO}_{3}$ could probably be adapted to the requirements of MHD seed recovery. This has been pointed out previously [1].

The commercial "Formate Process" involves the following:

1. Generation of calcium formate from $\mathrm{CO}$ and $\mathrm{Ca}(\mathrm{OH})_{2}$

2. Precipitation of calcium sulfate, leaving potassium formate in solution

3. Oxidation of potassium formate to potassium carbonate

At the carbonate stage, sodium can be separated from potassium by fractional crystallization. It might not be necessary to carry through the oxidation to carbonate, however if potassium could be introduced to the combustor as the formate. This should be studied. Potassium formate is $46 \mathrm{wt} \% \mathrm{~K}$; the remainder is combustible. Potassium carbonate is $56 \mathrm{wt} \% \mathrm{~K}$. Saturated potassium formate solution $\left(80^{\circ} \mathrm{C}\right)$ is $40 \mathrm{wt} \% \mathrm{~K}$ and $13 \mathrm{wt} \% \mathrm{H}, \mathrm{O}$. The remainder is combustible. $\mathrm{K}_{2} \mathrm{CO}_{3} \cdot 1 \cdot 5 \mathrm{H}_{2} \mathrm{O}\left(100^{\circ} \mathrm{C}\right)$ is $47 \mathrm{wt} \% \mathrm{~K}$ and $16 \mathrm{wt} \% \mathrm{H}_{2} \mathrm{O}$.

If, after severai cycles, the sodium content of the regenerated seed. builds up to unacceptably high levels, the Formate Process could be carried through to the carbonate, and the sodium carbonate could be separated by fractional crystallization.

\section{Reference}

1. AVCO Fuel Report to EPRI, MHD Power Generation EPRI 97, June 1975. 

Task K. MATERIALS TESTING AND COORDINATION (W. R. Hosler, H. P. R. Frederikse)

a. Plans for the U-02 Materials Test (Phase II)

Work for the implementation of Phase II of the US-USSR Cooperative Materials Testing Program is being continued. This test is scheduled to begin in mid-August 1976 and is to run for a minimum of 100 hours. Six materials will be tested in the U-02 channel using a configuration similar to that of the Phase I module. However, the electrode pitch and thermal gradients will be altered to correspond more closely to the geometry and heat fluxes of the channel being designed for the Soviet U-25 facility iwindow frame design, width per window $\sim 1 \mathrm{~cm}$ ). Other modifications will be made, based on the experience gained in the Phase I test, especially with respect to porosity and insulator geometry (to counteract seed penetration and thermal shock).

The Phase II-module is being designed and will be constructed by the Westinghouse Research Laboratories. NBS is keeping close contact with Dr. Rossing (Westinghouse) and with other contractors involved in the U-02 testing program. Samples of spinels have been prepared and sent to Westinghouse for possible use as Phase II electrodes. At the same time several candidate materials have been received from other organizations for the determination of structural and physical properties.

A work plan similar to the one for Phase I will be drafted.

b. Plans for the U-02 Materials Test (Phase III).

As mentioned under Task $\mathrm{H}$ the result of US-USSR discussions during the February meeting of the joint Materials Working Group is that both sides want to go ahead with the planning of a third materials test in the U-02 MHD-facility. The U.S. side has suggested to make the major goal of this experiment the testing of electrode and insulator materials under maintenance (replenishment) conditions. Furthermore, it was recommended that the maintenance materials will be Fe-Al-Silicate. More detailed plans both from the American and from the Soviet side will be submitted to the steering Committee in June 1976 (Washington, D. C.).

\section{c. Eost Test Analysis of AVCO MHD Channel Electrodes}

Eight electrode sections were obtained from the AVCO MHD channel subsequent to the ICO hour power run completed in late February. Each of these sections consists of twc or more electrode elements. Anode and cathode sections were taken from the upstream end of the channel where the "button" type construction was used and from the center of the channel length where rail type construction was used. A minimum of three slices from each section were cut perpendicular to the electrode surface and parallel to the plasma flow. This allows a cross sectional view of the electrode assembly with the slag in place above the electrode. Unfortunately, during the section removal from the channel, the slag chipped loose in some areas. As a result the cross section shows only proximal slag. All cross section pieces were held in place by epoxy pot.ting prior to the cutting process. The slag separation is not a serious difficulty since the SEM scans and microprobe can traverse this void area and pick-up the proximal slag without loss of information. 

Each slice will be examined in detail in all areas. A general montage of the electrode area will be made initially to identify those areas of particular interest. where information can be obtained to help ascertain the electrode erosion and corrosion problem.

The initial questions for which answers are sought in this investigation are:

1. What causes the unacceptable high rate of metal loss at the anode?

2. What is the charge transport mechanism in the slag layer and at the slag-metal interface on both anode and cathode?

3. What causes the erosion of copjer on the upstream side of the cathode electrode?

4. What causes a degradation of the cathode sidewall insulation?

Results: Slicing of the electrode sections is nearly complete. Several sections have been repotted for SEM and microprobe work and some information has been obtained concerning the chemical attack on the cathode. Erosion and corrosion effects on the cathode side are slight but still are readily observable. Detailed information about electrode effects - in particular, results that will help to answer the four questions stated above - will be forwarded to ERDA and AVCO when the analysis is completed.

Summary: Analysis of AVCO MHD channel electrodes has been started. The investigation will concentrate on the causes of the erosion and corrosion experienced during the recent 100 hour test. Final results and conclusions will be presented in a later quarterly report. 

Task L. ASSESSMENT OF STEAM PLANT COMPONENTS (J.R. Cuthi 11)

During this reporting period the first stage of Task $L$ has been completed. Our goal, which is to determine performance requirements, has been met in so far as projected values of gas temperatures, mass flow, and gas composition, and steam temperature and pressures have been forthcoming from computer mudel calculations. These "performance requirements" will be continually revised in forthcoming reports as refıned and additional data become available. For example, Figures $I$ i and 15 are updates of Figures 23 and 24 in the previous quarterly report, by the addition of design valut:s of steam temperatures and pressures of $1000^{\circ} \mathrm{F}$ and $3500 \mathrm{psi}$ steam leaving the Steam Super Heat, and $1000^{\circ} \mathrm{F}, 650$ psi steam leaving the Steam Reheat, labeled "Steam No. 1" and "Steam No.2", respectively. These values were obtained from the STD Corporation. With a steam temperature 0 e $1000^{\circ} \mathrm{F}$ on the inside of the boiler tube, the outside wall temperature of the tube (exposed to the flue gas) is estimated to be in the range of $1100^{\circ}-1200^{\circ} \mathrm{F}$.

We have turned our attention over to the second issue of this assessment study, having to do with the assembly of available data on potassium ion attack (here meant to refer to hot corrosion attack by potassium compounds). The test data obtained by the Bureau of Mines ${ }^{1}$ and in England, ${ }^{2}$ are virtually the only data on potassium ion hot corrosion attack. These test results were noted in the previous two quarterly progress reports. There is some work, currently, on the effect of pure potassium vapor on alloys, in connection with the development of the closedcycle potasssium vapor turbine scheme for electric power generation. ${ }^{3}$ It was reported that in potassium loop tests in the range of 1600 to $1800^{\circ} \mathrm{F}\left(870-990^{\circ} \mathrm{C}\right)$ at Oak Ridge, for the purpose of screening alloys for these turbines, types 304 , 316, and 321 stainless steels, Inconel 600, Hastelloy $x$, and Haynès 25 all resisted potassium attack. More relevant, however, is the considerable data in the literature on hot corrosion attack by $\mathrm{Na}_{2} \mathrm{SO}_{4}$ and, in lieu of potassium ion data, this has been used as a basis of selection of alloys included in the tables of property data. Of course, hot corrosion tests should be conducted in the actual potassium compounds involved, i.e., $\mathrm{K}_{2} \mathrm{SO}_{4}, \mathrm{~K}_{2} \mathrm{CO}_{3}$, and $\mathrm{KOH}$ probably being the most important ones, before final selections are made. A further search of the literature will be made for data on hot corrosion by potassium ions.

Data sheets were begun in the previous quarterly report, containing the reported values of the salient properties of certain promising alloys. This format is continued, and data on a number of new alloys with promising properties are included in this report. Particular attention should be paid to the relative amounts of the various species of "carbide: formers" in the "Alloy Compositions" table (Table IV). Rerent research has revealed that the hot corrosion pitting attack can be overcome by the substitution of $\mathrm{Hf}$ and $\mathrm{Ta}$ for the Mo and $\mathrm{W}$ as carbide formers. 4 (See Figure $1 \mathrm{~b}$ ). It is anticipated that modifications of some of the commercial alloys will be announced in the not too distant future as a result of this observation. It is interesting to note that molybdenum has the exact opposite effect here from its effect in another well-known type of pitting attack, i.e., molybdenum (precipitated as a carbide) is responsible for the pitting attack by molten sodium sulfate, but inhibits pitting by sodium chloride in aqueous solution. 

An additional column has been added to the "Mechanical Properties" table (Table V), for entering the ASME Boiler and Pressure Vessel Code maximum allowable design stresses as a function of temperature. Many of the alloys listed have already been approved as materials of construction for boiler tubes, etc., in present-day power plants. In doing so the maximum allowable stress to be used in design is specified as a function of metal wall temperature. Another column has also been added to the same table for listing comparative prices.

Another Table lists some of the "Thermal Properties" of these alloys (Table VI).

The INCO allcys added in this report are relatively new alloys but they have undergone extensive in-service testing as boiler tubing in conventional coal-fired and oil-fired power plants. In this type of service the producer recommends the following as maximum boiler tube wall temperatures:

\section{Alloy}

Inconel 617

Inconel 802

Inconel $800 \mathrm{H}$

Incoloy
Boiler Tube Metal Wall

Max. Temperature

There is need for more data on the resistance of the alloys to hot corrosion. Of course cladding is a way of obtaining both high strength together with high corrosion resistance or even aqueous chloride ion resistance on one side and resistance to $\mathrm{Na}_{2} \mathrm{SO}_{4}$ hot corrosion pitting on the other. The $671 / 800$ and the $671 / 800 \mathrm{H}$ are the only clad products in this category of alloys that have been produced commercially but, if the combination of high strength and maximum hot corrosion resistance is

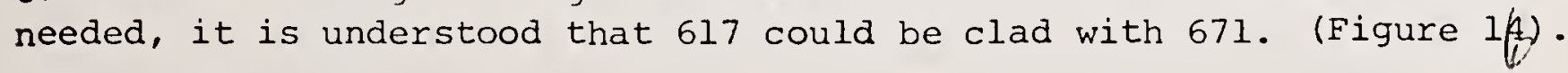

\section{Future Plans}

Additional comparison cost figures and additional key property data on the alloys listed in the Mechanical and Thermal Properties Tables, will be obtained. The alloys listed thus far have been selected primarily on the basis of the anticipated boiler tube requirements. It is not to be implied that this list is complete as regards promising boiler tube alloys; in addition to new alloys, many of the alloys listed have equivalent counterparts by other trade designations and of course produced by other mills. Additional alloys will be added in future reports.

In addition, in future reports, a summary of promising hasa facing alloys and surface treatments for valve seats will be compiled with primarily the valves of the regenerative air preheater in mind.

\section{References}

1. D. Bienstock, R. J. Demski, R. C. Corey, "Corrosion of Heat-Exchange Tubes in a Simllated Coal-Fired MHD System", Journ. of Engineering Power, 93, Series A, No. 2, pp. 249-256 (1971) (Trans. of ASME). 

2. J. B. Haywood and G. J. Womach, ed., "Open-Cycle MHD Power Generation". C 1969, Pergamon Press.

3. W. F. Zimmerman and R. G. Frank, "Materials Requirements for the Alkali Metal Topping Cycle", 105th AIME Annual Meeting, Las Vegas, Feb. 22-26, 1976.

4. J. H. Wood, D. A. Shores, N. R. Lindblad, "Control of MC Carbide Composition for. Improved Hot Corrosion Resistance in a Nickel Base Superalloy", 105th AIME Annual Meeting, Las Vegas, Feb. 22-26, 1976. 



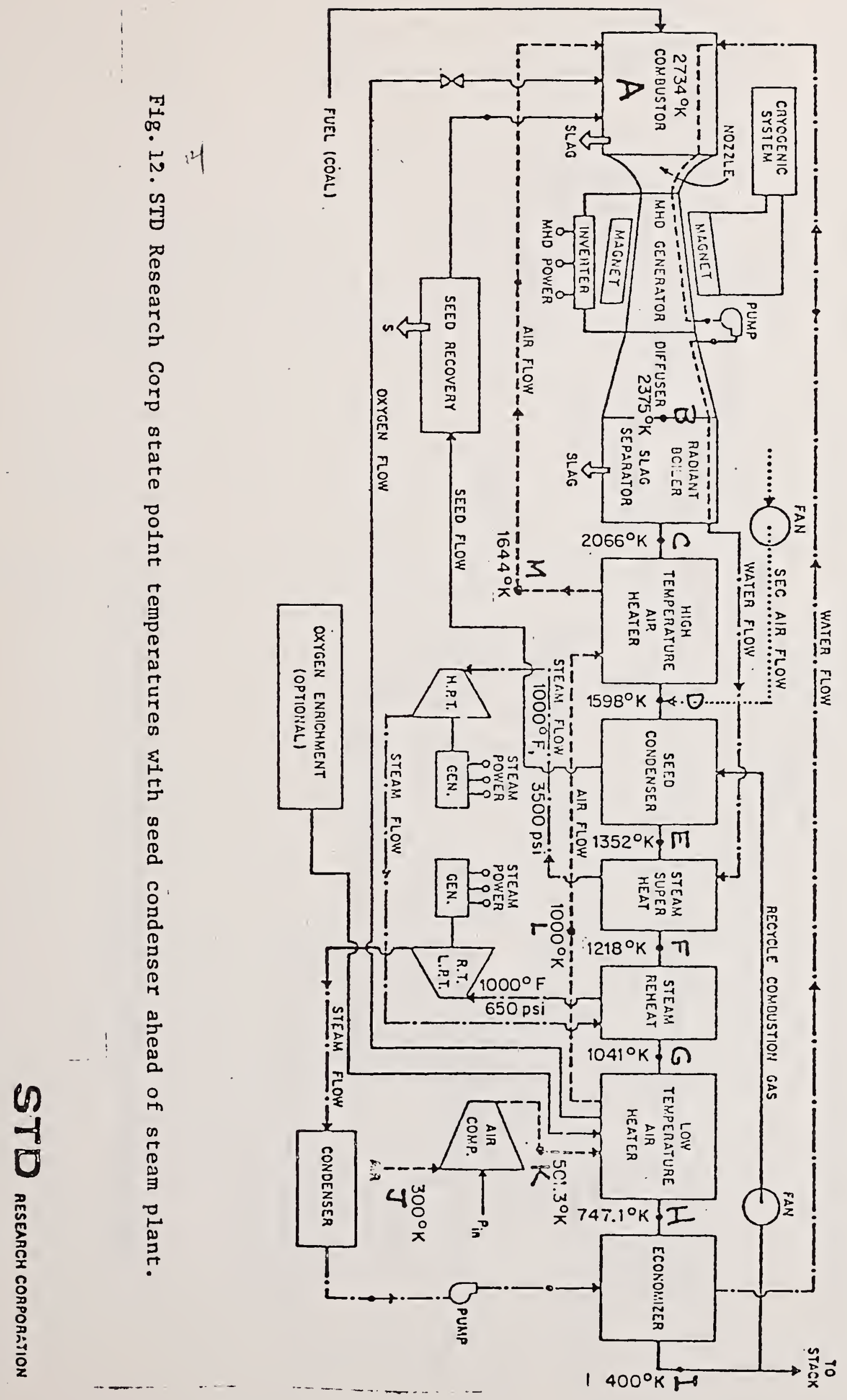




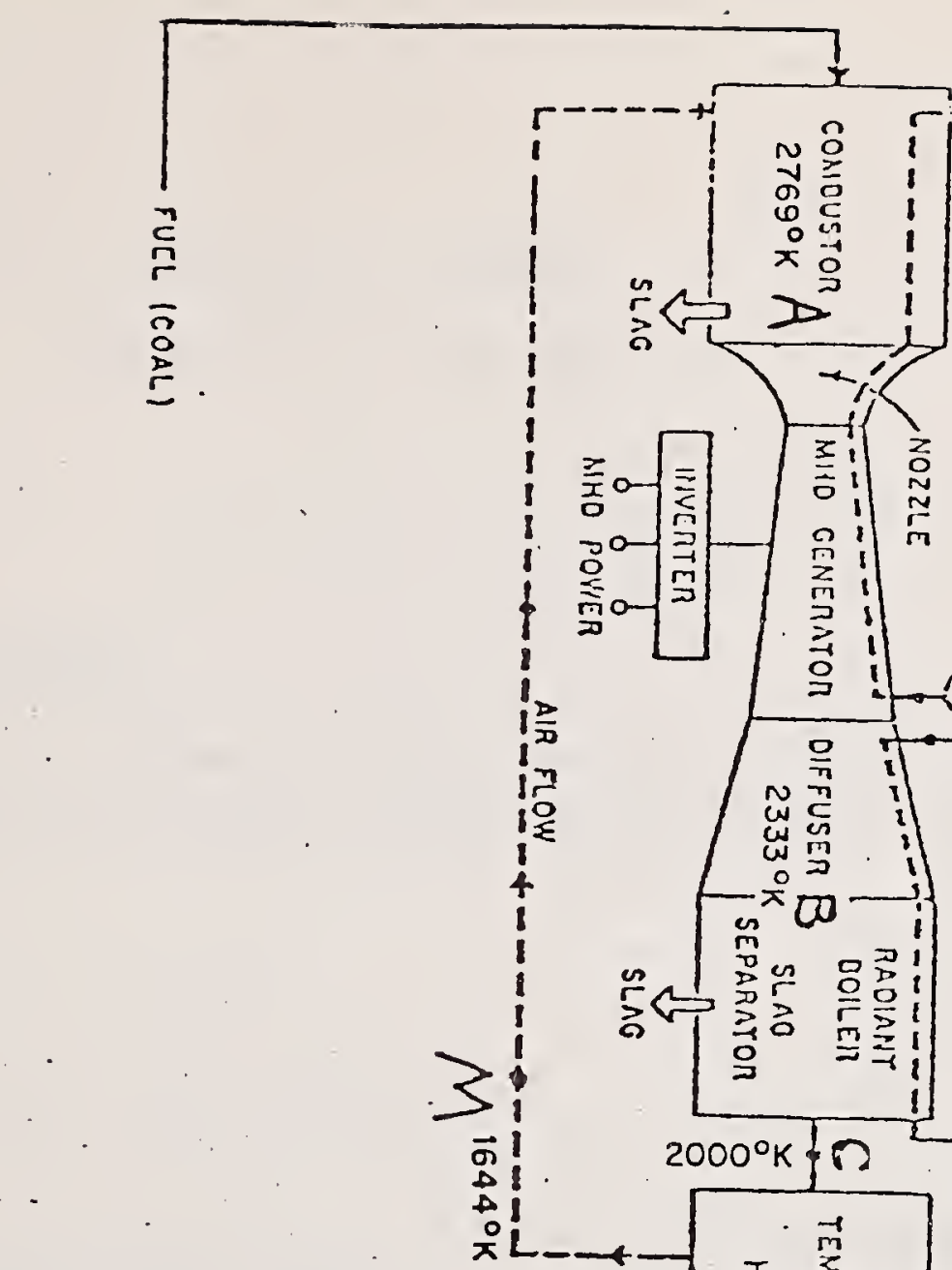

남
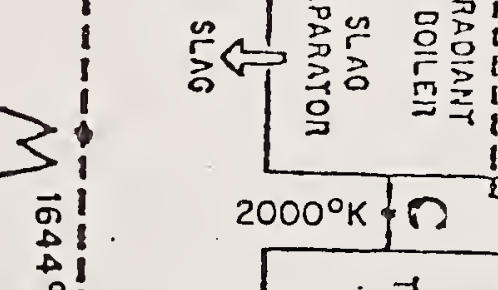

.
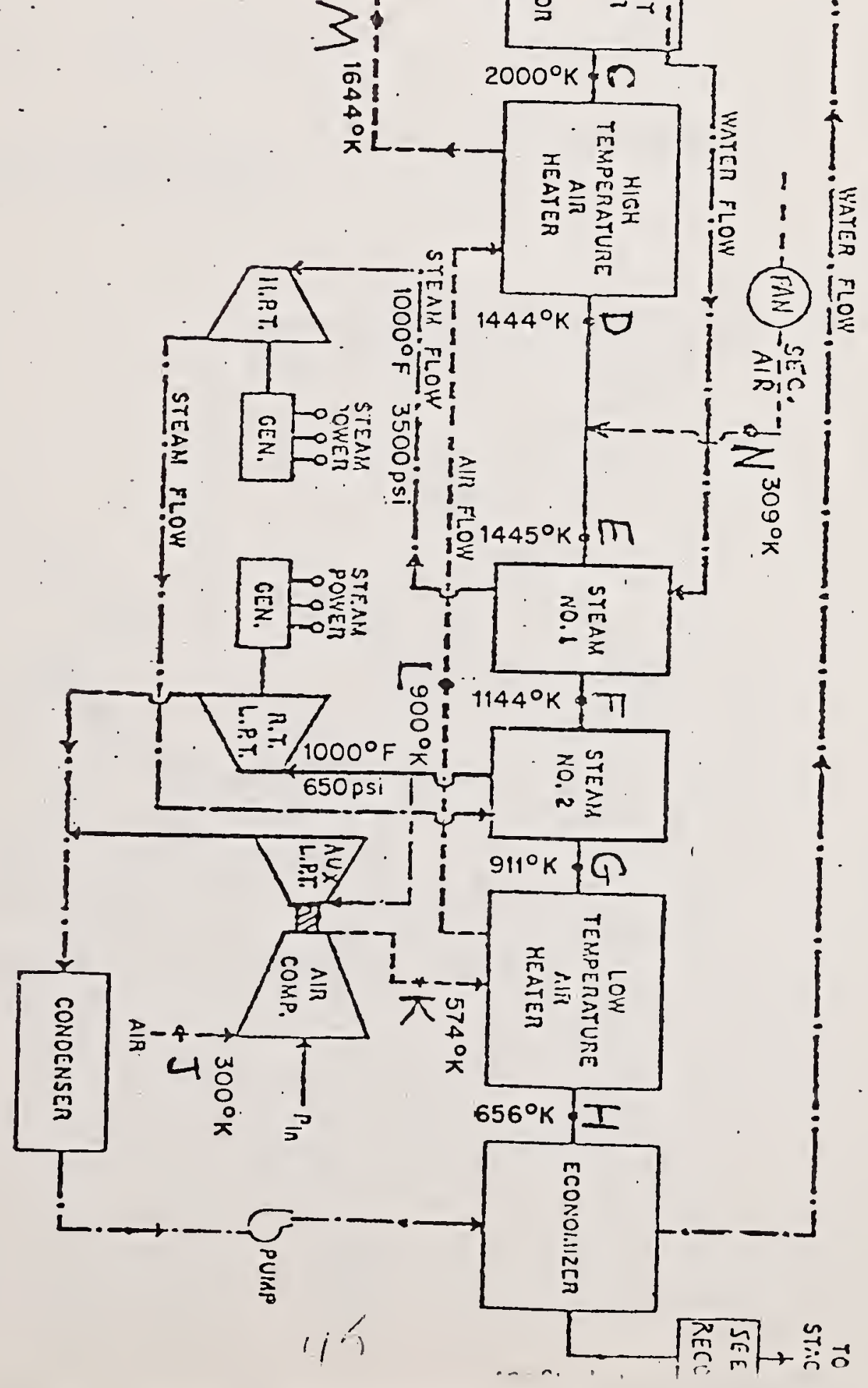

$1444^{\circ} \mathrm{K}=0$

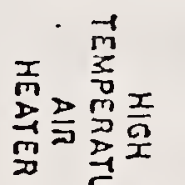



Fig. 14. HOT CORROSION PITTING

Reported Cause and Cure

\section{Mechanism of pit formation}

Mo or $W$ carbides in surface convert to oxides which are highly soluable in the molten $\mathrm{Na}_{2} \mathrm{SO}_{4}$, making it more acidic and much more aggressive.

\section{Solution}

Replace the Mo and $W$ with Ta and/or Hf

Pit filled with corrosion products at location of former Mo or $W$ carbide particle in the alloy surface

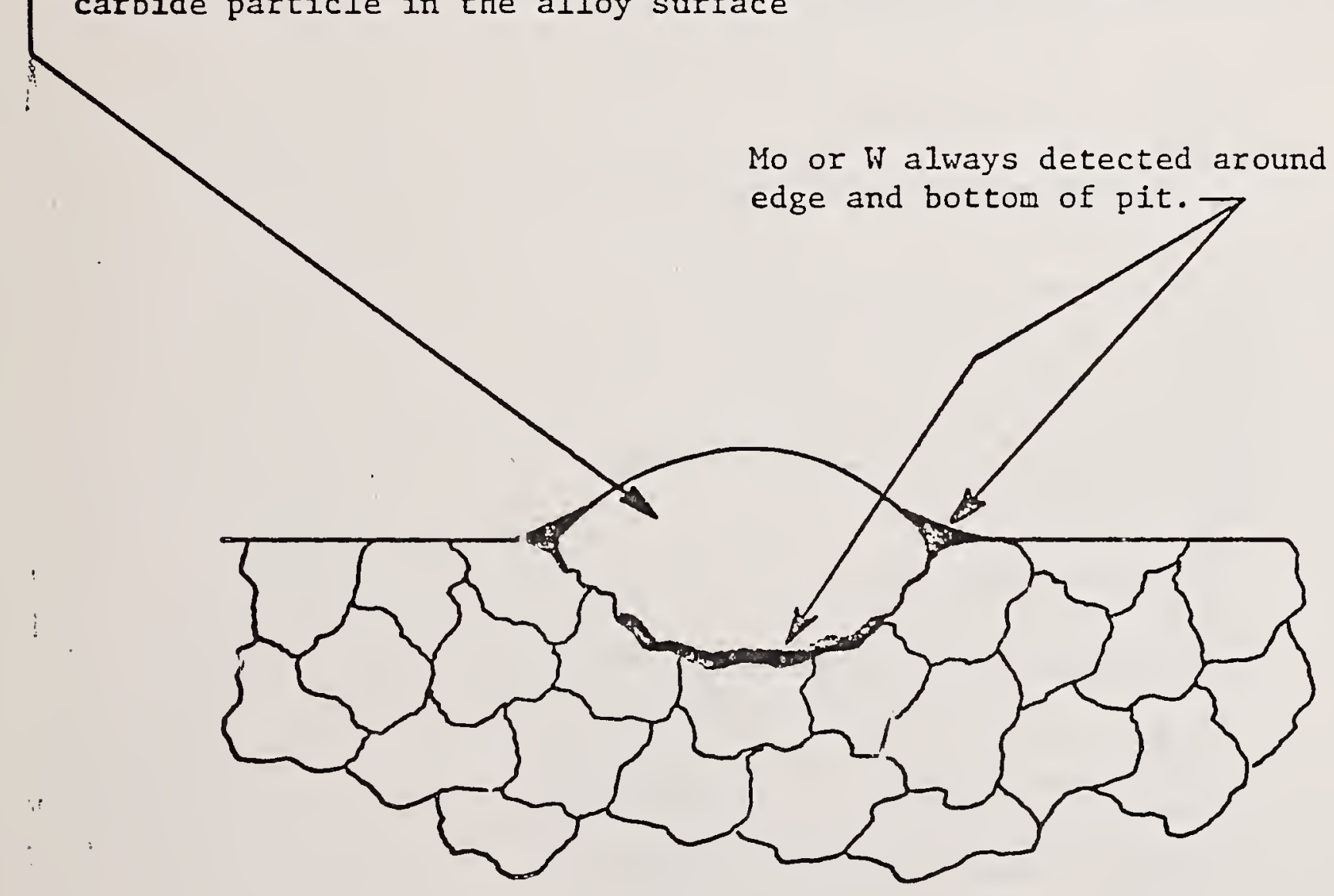





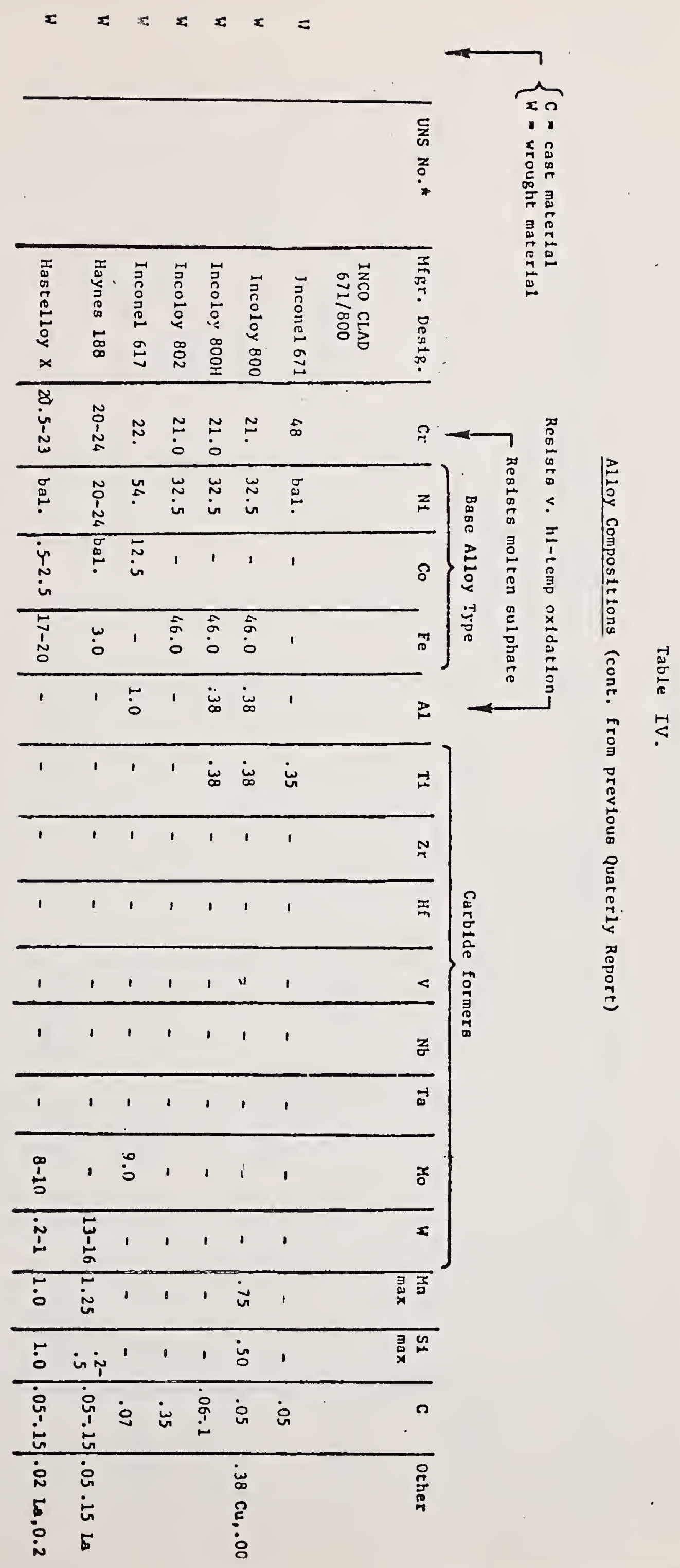





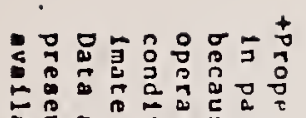

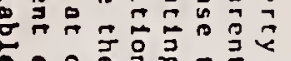

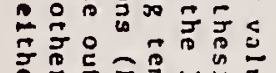
等

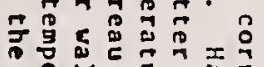

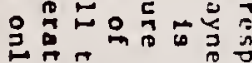

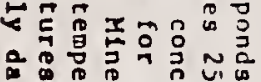

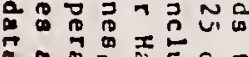

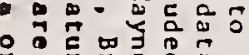
का है

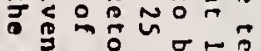

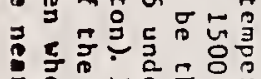

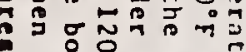

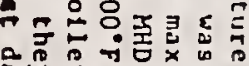

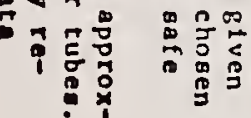

ఏ EEDE

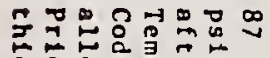

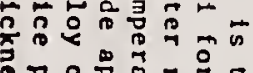

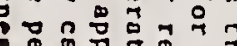
일

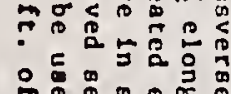
음

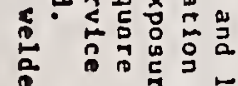
ล ह 曋 ก โ o :

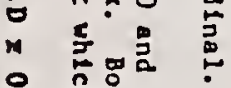

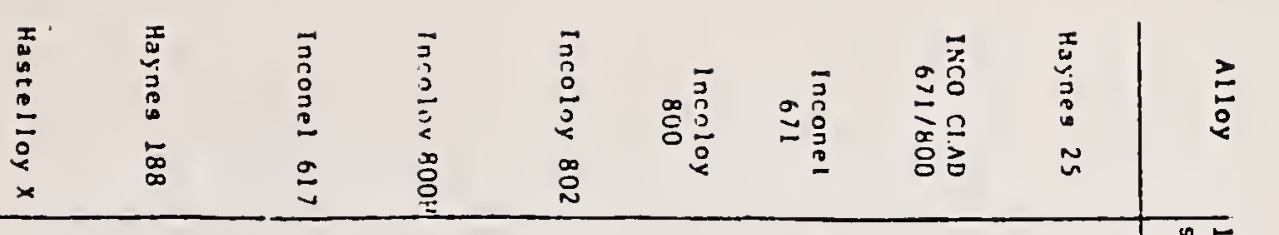

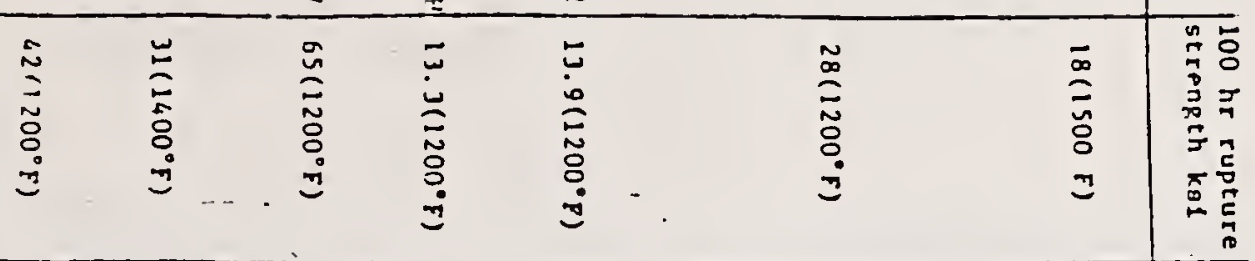

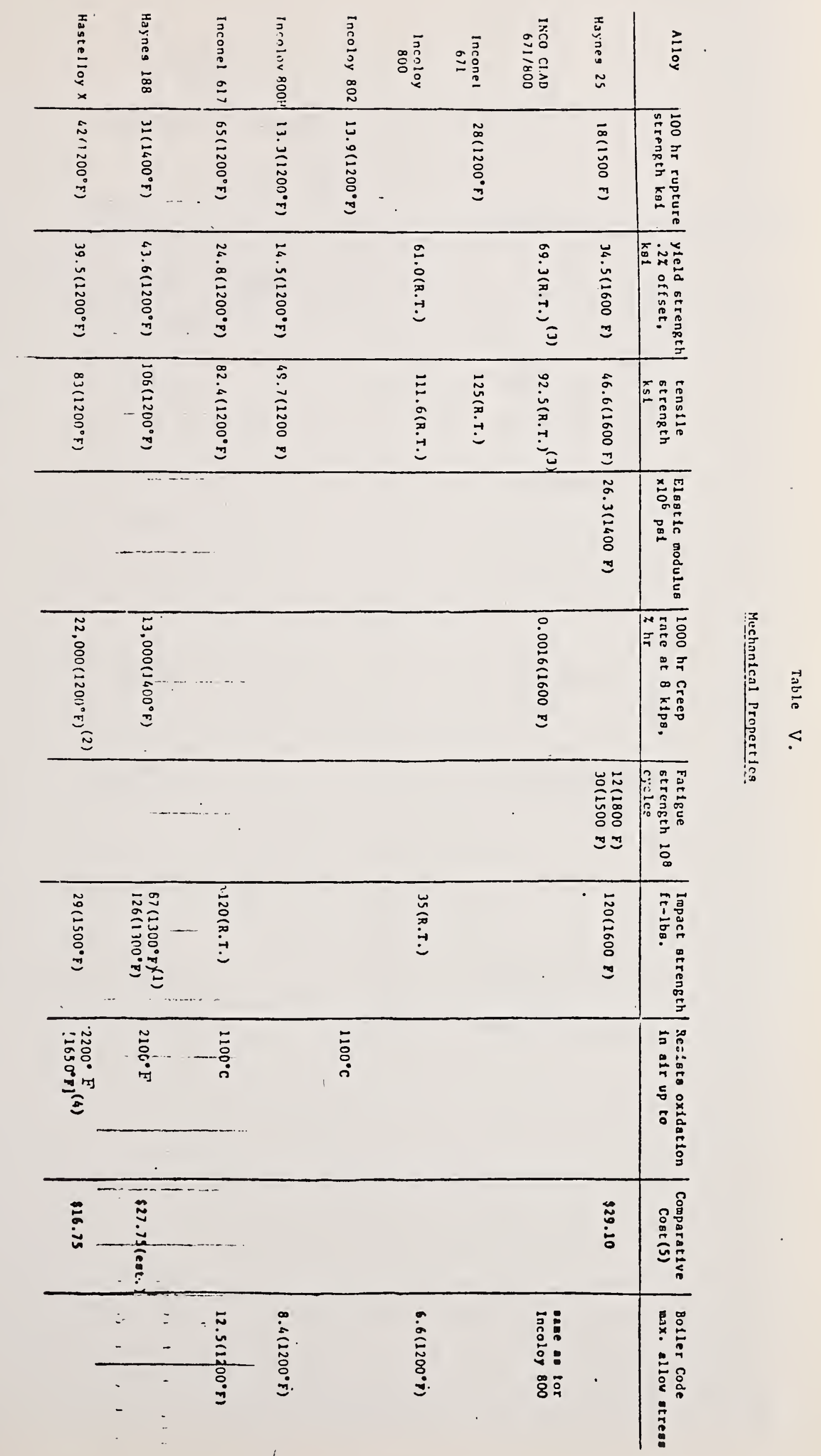
둥 

Table VI.

Thermal Properties

\begin{tabular}{|c|c|c|}
\hline Alloy & $\begin{array}{l}\text { Thermal } \\
\text { Conductivity } \\
\text { BTU/hr./sq.ft./ F/ft. }\end{array}$ & $\begin{array}{c}\text { Mean Coef. of Thermal Exp. } \\
\qquad \times 10^{-6} /{ }^{\circ} \mathrm{F}\end{array}$ \\
\hline Haynes 25 & $15.9\left(1200^{\circ} \mathrm{F}\right)$ & $9.4(70-1800 \mathrm{~F})$ \\
\hline 310 S.S. & $8.2(212 \mathrm{~F})$ & $8.8(32-212 \mathrm{~F})$ \\
\hline 316 S.S. & $9.4(212 \mathrm{~F})$ & $8.9(32-212 \mathrm{~F})$ \\
\hline 446 S.S. & $14.3(68-932 \mathrm{~F})$ & $7.4(68-1832 \mathrm{~F})$ \\
\hline IN713C & $18.3(1600 \mathrm{~F})$ & $8.6(70-1600 \mathrm{~F})$ \\
\hline U500 & $14.1(1600 \mathrm{~F})$ & $8.9(70-1600 \mathrm{~F})$ \\
\hline FSX418 & $\ldots$ & \\
\hline WI52 & $15.8(1300 \mathrm{~F})$ & $8.8(70-1800 \mathrm{~F})$ \\
\hline INCO CLAD $671 / 800 \mathrm{H}$ & & \\
\hline $\begin{array}{l}\text { Inconel } 671 \\
\text { Incoloy } 800\end{array}$ & $9.1\left(70^{\circ} \mathrm{F}\right)$ & $7.99\left(78-1200^{\circ} \mathrm{F}\right)$ \\
\hline Inconel 617 & & \\
\hline Incoloy $800 \mathrm{H}$ & & \\
\hline Haynes 188 & $12.7\left(1200^{\circ} \mathrm{F}\right)$ & $8.6\left(70-1200^{\circ} \mathrm{F}\right)$ \\
\hline Hastelloy $\mathrm{X}$ & $13.3\left(1300^{\circ} \mathrm{F}\right)$ & $8.6\left(79-1200^{\circ} \mathrm{F}\right)$ \\
\hline
\end{tabular}


